\title{
Systematic literature review of treatment patterns for venous thromboembolism patients during transitions from inpatient to post-discharge settings
}

This article was published in the following Dove Press journal:

ClinicoEconomics and Outcomes Research

Jeffrey Trocio'

Virginia M Rosen ${ }^{2}$

Anu Gupta ${ }^{3}$

Oluwaseyi Dina'

Lien Vo ${ }^{4}$

Patrick Hlavacek'

Lisa Rosenblatt ${ }^{5}$

'US Health Economics and Outcomes Research Pfizer Inc., New York, NY, USA; ${ }^{2}$ Health Economics and Outcomes Research, Optum Inc., Eden Prairie, MN, USA; ${ }^{3}$ US Medical Affairs, Pfizer Inc., New York, NY, USA; ${ }^{4}$ US Health Economics and Outcomes Research, Bristol-Myers Squibb, Lawrenceville, NJ, USA; ${ }^{5}$ US Medical Affairs, Bristol-Myers Squibb, Lawrenceville, NJ, USA
Correspondence: Oluwaseyi Dina Pfizer Inc., 235 East 42nd Street, New

York, NY 10017 , USA

Tel +l 2I27338393

Email Oluwaseyi.Dina@pfizer.com
Introduction: Direct oral anticoagulants (DOACs) have emerged as viable alternatives to traditional treatments such as vitamin $\mathrm{K}$ antagonists (VKAs) for venous thromboembolism (VTE). The objective of this review was to summarize evidence on the use of DOACs and VKAs to treat VTE in the US for patients transitioning from inpatient to post-discharge settings.

Materials and methods: A systematic review of the VTE literature identified studies published in English (January 1, 2011-December 31, 2016) that reported inpatient and post-discharge treatments and discharge location. Two reviewers screened abstracts, abstracted information from included studies, and assessed the quality of the study methodology and reporting.

Results: Forty-nine studies were included ( 24 clinical and 25 economic). A limited number of studies (eight clinical and three economic) examined VTE treatment patterns during transitions of care from inpatient to post-discharge settings, irrespective of anticoagulant (eg, DOAC, warfarin, heparin), and $<25 \%$ of all studies reported a post-discharge location. Three clinical studies that reported inpatient and outpatient treatment found better patient outcomes with DOAC vs warfarin. Fourteen economic studies reported that DOACs were associated with shorter hospital length of stay (LOS) and lower direct costs vs warfarin. No studies reported indirect costs.

Discussion: Although DOACs are associated with shorter LOS, lower costs, and better patient outcomes vs VKAs, it appears in one study that only a small percentage of patients with stable VTE who are discharged to home may be receiving DOACs.

Conclusion: These findings identified the potential areas of opportunity to improve the management of VTE through coordination of care from the inpatient to the outpatient settings.

Keywords: deep vein thrombosis, pulmonary embolism, anticoagulant, transition of care

\section{Introduction}

The number of adults with venous thromboembolism (VTE) in the US between 2002 and 2006 was estimated to be 1 million individuals, and this estimate is expected to double by $2050 .{ }^{1}$ Furthermore, the Centers for Disease Control and Prevention reported that approximately 500,000 individuals in the US were hospitalized for VTE during the period 2007-2009. ${ }^{2}$ The VTE-related cost estimate for 2014 ranged from $\$ 7$ billion to $\$ 10$ billion based on $375,000-425,000$ incident cases in the US. ${ }^{3}$ On a per-patient basis, 2014 annual incident costs were estimated at $\$ 12,000-\$ 15,000 .^{3}$

VTE treatment guidelines recommend anticoagulant therapy for 3 months following an acute event, with subsequent long-term or extended therapy depending on patient's risk of recurrence. ${ }^{4}$ Other treatments include thrombolytics, the insertion of 
an inferior vena cava filter (IVCF), or a procedure to remove the clot (thrombectomy/embolectomy). Anticoagulant treatment options include the use of traditional oral and injectable therapies as well as the more recently developed direct oral anticoagulants (DOACs). Until 2009, vitamin K antagonists (VKAs) - primarily warfarin - were the only type of oral anticoagulant available. VKAs are effective in treating VTE, but they require frequent monitoring and have significant drug and food interactions. Indirect or injectable anticoagulants (IACs) include unfractionated heparin, low-molecular-weight heparin (LMWH; eg, enoxaparin), and fondaparinux. Currently, there are four DOAC therapies (dabigatran, rivaroxaban, apixaban, and edoxaban) available in the US, and each has been shown to be noninferior to VKAs in the treatment of VTE. ${ }^{4-7}$ Because patients who are receiving DOAC therapies do not need heparin bridging and frequent monitoring DOACs may allow stable patients with VTE to be treated at home earlier than with VKAs.

Irrespective of type of anticoagulant used, once the acute event is addressed in the inpatient (IP)/emergency department (ED) setting, the condition is then managed in various health care (outpatient [OP], home care, and long-term care) settings and by a number of specialty types. ${ }^{8}$ As such, successfully managing treatment of a VTE patient as care transitions between IP and OP settings can positively impact patient outcomes, as evidenced by a decrease in length of stay $(\mathrm{LOS})^{9}$ and the likelihood of readmission. ${ }^{10}$ For VTE patients, successful transition of care relies on effective communication and coordination between clinicians and their patients/care takers, as well as patient adherence to the treatment regimen. ${ }^{11}$

The objectives of this review were to summarize the literature regarding the treatment of VTE with DOACs and VKAs in the IP and OP setting and to determine discharge location after patients leave the IP setting. Specifically, this review examines IP and OP treatment patterns, post-discharge location (eg, home, skilled nursing facility [SNF]), patient outcomes (eg, treatment adherence), and health care resource utilization (eg, hospital LOS) and costs (eg, direct, indirect) associated with VTE for patients who are transitioning from IP to OP settings.

\section{Materials and methods}

The literature review followed the PRISMA guidelines. ${ }^{12,13}$ The databases that were searched were PubMed/MEDLINE, EMBASE, and the Cochrane Library. The appendix contains the clinical and economic search strategies (Tables S1 and S2, respectively) that display the Medical Subject
Heading $(\mathrm{MeSH})$ terms and keywords used in the search of the PubMed/MEDLINE database. The clinical search was directed at identifying the studies that reported IP and OP treatment patterns and clinical outcomes associated with VTE, irrespective of the study design. Similarly, the economic search was directed at identifying the studies that reported VTE-associated IP and OP health care resource utilization and costs, irrespective of the study design. For simplicity and consistency, we will refer to the studies retrieved from the clinical search as "clinical studies" and will likewise refer to the studies retrieved from the economic search as "economic studies". The systematic searches were supplemented by a manual review of bibliographies. Articles published in English that reported IP and post-discharge treatments for VTE published between January 1, 2011, and December 31, 2016, were included in the review. Studies were excluded during the abstract screening process if they were case studies, letters to the editor, editorials, commentaries, reviews, and studies that did not report patient outcomes (eg, study protocols) or studies that were conducted outside of the US.

Two reviewers independently screened the abstracts that were retrieved from the searches and also abstracted information for the final set of studies that were included in the review, using the same data abstraction form. During the abstraction process, the two reviewers also assessed the study methodology and reporting using the nonrandomized control trial (non-RCT) checklist from the National Institute for Health and Clinical Excellence (NICE) ${ }^{14}$ for the clinical studies and the 2013 version of the Consolidated Health Economic Evaluation Reporting Standards (CHEERS) ${ }^{15}$ checklist for the economic studies. Any discrepancies between the two reviewers during the screening or abstraction process were resolved by consensus, and a third reviewer adjudicated unresolved disputes; the judgment of the third reviewer was considered final.

The four quality assessment categories from the NICE methodology that were used to assess the clinical studies included 1) selection bias, defined as systematic differences between the comparison groups; 2) performance bias, defined as systematic differences between the groups in the care provided, apart from the intervention under investigation; 3) attrition bias, defined as systematic differences between the comparison groups with respect to loss of participants; and 4) detection bias, defined as bias in how outcomes are ascertained, diagnosed, or verified. The economic studies were assessed using the CHEERS checklist that has 24 items with two-thirds of the items directed at the reporting of study methodology and with many items pertaining to economic models 
rather than observational studies such as those included in this literature review. Consequently, model-related items that could not be assessed received a not applicable (NA) rating.

\section{Results}

\section{Study selection and characteristics}

The systematic searches of the PubMed/MEDLINE, EMBASE, and Cochrane Library databases retrieved 1,415 abstracts from the clinical search and 139 abstracts from the economic search, of which 1,391 clinical and 114 economic studies were excluded with reasons. Figures 1 and 2 show the PRISMA flow diagrams that display the clinical and economic search and review process, respectively, and the reasons for study exclusion. After completing the screening process and a full-text review, 24 clinical and 25 economic studies were included in the literature review.

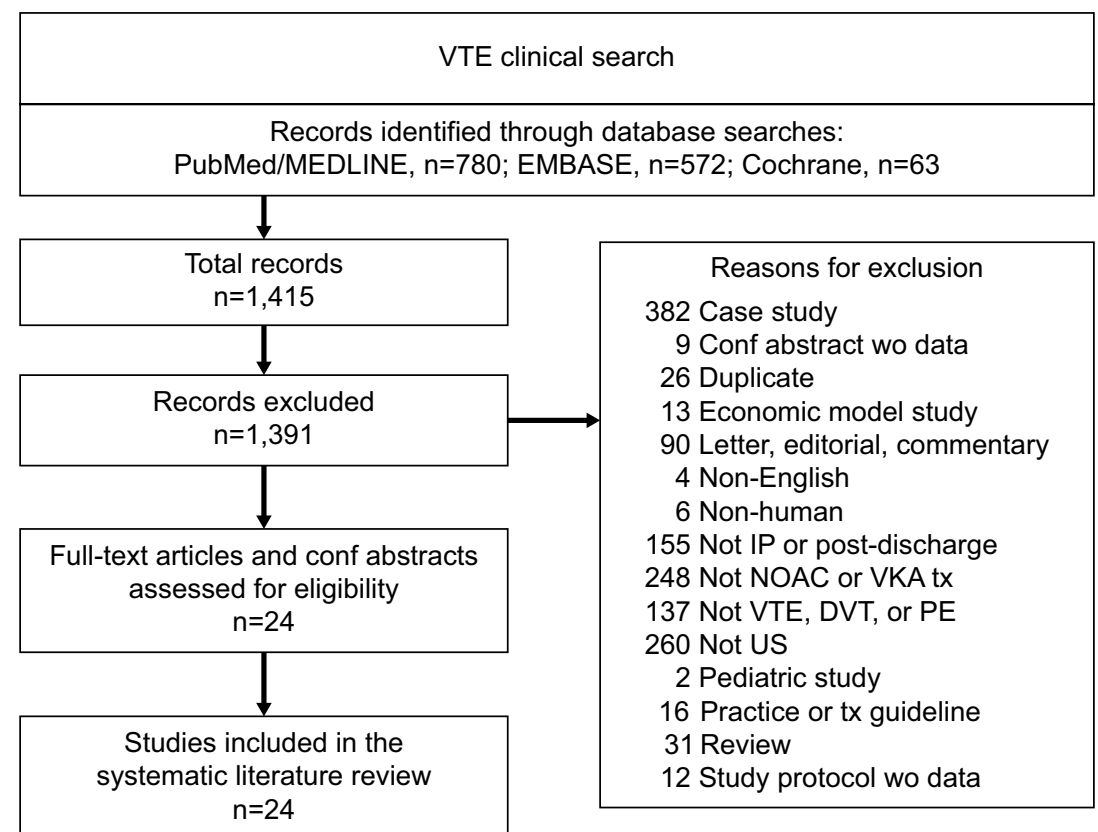

Figure I Clinical search results.

Abbreviations: Conf, conference; DVT, deep vein thrombosis; IP, inpatient; NOAC, new/novel oral anticoagulant; PE, pulmonary embolism; tx, treatment; VKA, vitamin K antagonist; VTE, venous thromboembolism; wo, without.

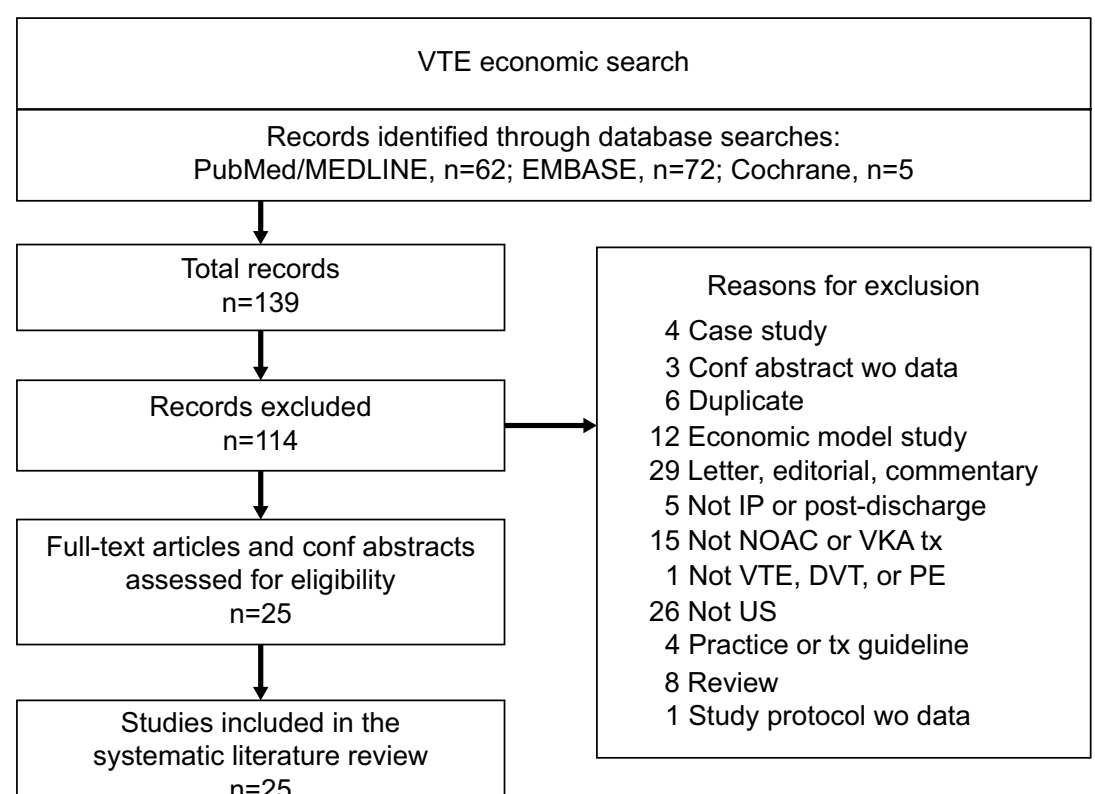

Figure 2 Economic search results.

Abbreviations: Conf, conference; DVT, deep vein thrombosis; IP, inpatient; NOAC, new/novel oral anticoagulant; PE, pulmonary embolism; tx, treatment; VKA, vitamin K antagonist; VTE, venous thromboembolism; wo, without. 
Table 1 displays the study characteristics for the 24 clinical and 25 economic studies that were included in the review. Across all studies, the mean age reported ranged between 47.0 and 69.2 years, and the percentage of patients who were male ranged between $33.8 \%$ and $61.5 \%$. Less than $25 \%$ of all studies reported a discharge location. The lack of reporting on discharge location may be in part due to the finding that
38 of the 49 studies $(78.0 \%)$ were conducted retrospectively and 28 of these 38 studies ( $73.7 \%$ ) used administrative claims data which is a data source that does not typically contain information about discharge location.

Table 2 displays the number of studies reporting IP and OP treatments and outcomes. A little more than two-thirds of the studies reported an IP treatment $(n=34)$, and about half

Table I Study characteristics

\begin{tabular}{|c|c|c|c|}
\hline Characteristics & $\begin{array}{l}\text { All studies } \\
(n=49)\end{array}$ & $\begin{array}{l}\text { Clinical studies } \\
(n=24)\end{array}$ & $\begin{array}{l}\text { Economic studies } \\
(n=25)\end{array}$ \\
\hline \multicolumn{4}{|l|}{ Patient demographics } \\
\hline Mean age (years), range & $47.0-69.2$ & $47.0-68.7$ & $47.2-69.2$ \\
\hline$\%$ Male, range & $33.8-61.5$ & $40.0-61.5$ & $33.8-58.8$ \\
\hline \multicolumn{4}{|l|}{ Populations reported, n (\%) } \\
\hline VTE & $13(26.5)$ & $4(8.2)$ & $9(18.4)$ \\
\hline DVT only & $9(18.4)$ & $7(14.3)$ & $2(4.1)$ \\
\hline PE only & II (22.4) & $4(8.2)$ & $7(14.3)$ \\
\hline DVT+PE combination & $14(28.6)$ & $9(18.4)$ & $5(10.2)$ \\
\hline VTE+atrial fibrillation & $2(4 . I)$ & - & $2(4.1)$ \\
\hline \multicolumn{4}{|c|}{ Discharge location reported, $\mathrm{n}(\%)$} \\
\hline Studies reporting discharge & II (22.4) & $7(29.2)$ & $4(16.0)$ \\
\hline Home & $6(12.2)$ & $5(10.2)$ & $\mathrm{I}(2.0)$ \\
\hline Home or skilled nursing & $3(6.1)$ & - & $3(6.1)$ \\
\hline OP (nonspecified) & $3(6.1)$ & $2(4.1)$ & $\mathrm{I}(2.0)$ \\
\hline IP-only study & $17(34.7)$ & $7(14.3)$ & $10(20.4)$ \\
\hline Not reported & $21(40.8)$ & $10(20.4)$ & II (20.4) \\
\hline
\end{tabular}

Note: Studies may report more than one type of discharge location.

Abbreviations: DVT, deep vein thrombosis; IP, inpatient; OP, outpatient; PE, pulmonary embolism; VTE, venous thromboembolism.

Table 2 Number of studies reporting treatments and outcomes

\begin{tabular}{|c|c|c|c|}
\hline Characteristics & $\begin{array}{l}\text { All studies } \\
(n=49)\end{array}$ & $\begin{array}{l}\text { Clinical studies } \\
(n=24)\end{array}$ & $\begin{array}{l}\text { Economic studies } \\
(n=25)\end{array}$ \\
\hline \multicolumn{4}{|l|}{ Treatments reported $(n)$} \\
\hline IP DOAC & 27 & 14 & 13 \\
\hline IP VKA & 25 & 13 & 12 \\
\hline IP IAC & 22 & 12 & 10 \\
\hline IP treatment not reported & 15 & 5 & 10 \\
\hline OP DOAC & 13 & 8 & 5 \\
\hline OP VKA & 16 & II & 5 \\
\hline OPIAC & 9 & 5 & 4 \\
\hline OP treatment not reported & 26 & 12 & 14 \\
\hline Reported both IP and OP treatment & 11 & 8 & 3 \\
\hline \multicolumn{4}{|l|}{ Outcomes reported $(n)$} \\
\hline Hospital length of stay & 25 & 11 & 14 \\
\hline Time to discharge & 7 & 5 & 2 \\
\hline Readmission & 12 & 5 & 7 \\
\hline Treatment response & 8 & 8 & - \\
\hline Complications & 17 & 8 & 9 \\
\hline Treatment discontinuation & 4 & 4 & - \\
\hline Mortality & 19 & 8 & 11 \\
\hline Treatment adherence & 6 & 6 & - \\
\hline Health care resource utilization & 22 & 12 & 10 \\
\hline Health care costs & 28 & 3 & 25 \\
\hline
\end{tabular}

Note: Studies may report more than one type of treatment and/or outcome.

Abbreviations: DOAC, direct oral anticoagulant; IAC, indirect or injectable anticoagulant; IP, inpatient; OP, outpatient; VKA, vitamin K antagonist. 
reported an OP treatment $(n=23)$. Eleven of the 49 studies (22.4\%) reported both an IP and an OP treatment. Of note, the study counts are not mutually exclusive, and the 11 studies that reported both IP and OP treatments are included in the counts of studies reporting either an IP or an OP treatment separately. The most frequent IP treatments reported were DOACs $(n=27)$, followed by VKAs $(n=25)$, and then IACs $(n=22)$. The most frequent OP treatments reported were VKAs ( $n=16$; warfarin), followed by DOACs $(n=13)$, and then IACs $(n=9)$. The most frequent outcomes reported across the 49 studies included hospital LOS $(n=25)$, health care resource utilization $(n=22)$, mortality $(n=19)$, complications $(n=17)$, and costs $(n=28)$. Of note, only 11 of the 49 studies $(22.4 \%)$ reported a discharge location, and none of the studies reported indirect costs.

\section{Quality assessment of study methodology and reporting}

Table 3 contains a "NICE Quality Assessment" column with the ratings of bias for each clinical study using the NICE methodology, and Table 4 contains a "CHEERS Quality Assessment Deficient Items" column with a listing of the deficient or missing checklist items for each economic study using the CHEERS checklist methodology.

\section{NICE assessment}

Because 21 of the 24 clinical studies had retrospective designs, performance and attrition bias for these studies could not be assessed. With respect to selection bias, five studies were rated as having a low risk, eight studies were rated as having an unclear risk, and 11 studies were rated as NA for selection bias. For the four studies that were rated for attrition bias, three studies had a low risk and one study had an unclear risk because of the lack of detail reported (ie, conference abstract). Finally, 23 studies were rated as having a low risk of detection bias, and one study was rated as NA for detection bias.

\section{CHEERS assessment}

Overall, most of the studies received a "Yes" for identifying the study as an economic evaluation in the title and abstract (items 1-3); for providing a clear study objective and description of the population and setting (items 4 and 5 ); for explaining the choice of outcomes (items 7, 8, and 10); for a complete reporting of the results (items 18 and 19), discussion, and limitations (item 22); and for reporting conflict of interest and sources of support (items 23 and 24). Only a handful of studies received a rating of "No" for the lack of reporting on various items, except for the discount rate item (item nine) where none of the 25 studies reported a discount rate.

\section{Outcomes (clinical search)}

Table 3 displays the study details and findings for the 24 clinical studies that were included in the review following the search on clinical outcomes. Twenty-one studies had a retrospective design, one study was a prospective cohort study, and two studies identified patients retrospectively and then followed them prospectively.

Of the eight studies reporting both IP and OP treatments, seven reported both IP and OP DOAC use ${ }^{16-22}$ (rivaroxaban, dabigatran, and apixaban), five reported IP VKA use ${ }^{17-19,21,22}$ (warfarin) and seven reported OP VKA use ${ }^{17-23}$ (warfarin), six reported IP IAC use,,$^{17,18,20-23}$ (enoxaparin and LMWH), and four reported OP IAC use ${ }^{17,18,21,22}$ (enoxaparin and LMWH).

Seventeen of the 24 studies $(71.0 \%)$ did not report discharge location, seven of which were IP-only studies. When examining IP and OP treatments, and post-discharge location, eight of the 24 studies reported both IP and OP treatments and three of these eight studies reported discharge to home. ${ }^{20-22}$ Among the 16 studies that did not report both IP and OP treatments, four studies reported discharge location including one study ${ }^{24}$ that reported that patients were discharged to either home or a SNF, one study ${ }^{25}$ that reported that patients were discharged to home, and two studies ${ }^{26,27}$ that reported that patients were discharged to an OP setting but did not provide further detail about the OP setting.

With respect to hospital LOS, 11 of the 24 studies reported LOS, and among this group of studies, five ${ }^{18,28-31}$ reported shorter hospital LOS for patients who received rivaroxaban vs warfarin with mean LOS ranging from 1.8 to 3.7 days for rivaroxaban and from 3.8 to 7 days for warfarin.

With respect to patient outcomes associated with IP and OP treatment, four studies reported both IP and OP treatment and treatment-related outcomes with two of the studies examining outcomes for patients discharged from the ED. Beam et $\mathrm{al}^{20}$ examined whether DVT and/or PE could be successfully treated at home with a DOAC (rivaroxaban) for patients discharged from the ED. After 1 year of follow-up, none of the 106 patients in the study had VTE recurrence or a major or clinically relevant bleeding event while on therapy; however, three patients had recurrent DVT after stopping therapy. The second study was conducted by Falconieri et $\mathrm{al}^{21}$ who examined the use of a transition of care program (facilitating anticoagulation for safer transitions [FAST]) for treating patients with DVT who presented with an acute uncomplicated DVT in the ED. 


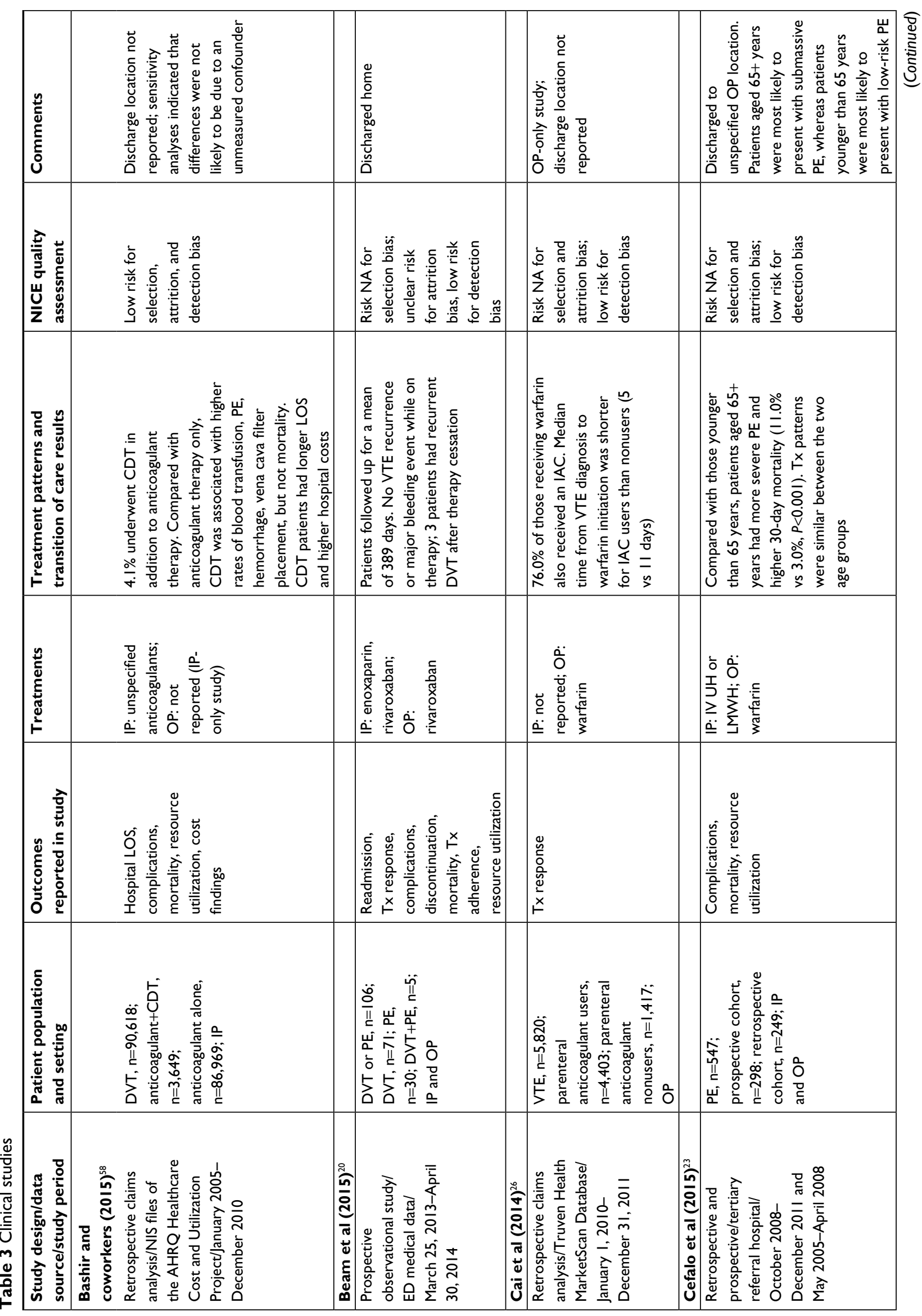




\begin{tabular}{|c|c|c|c|c|c|c|c|}
\hline 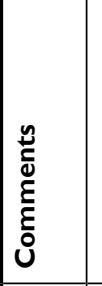 & 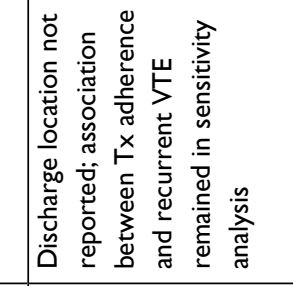 & & 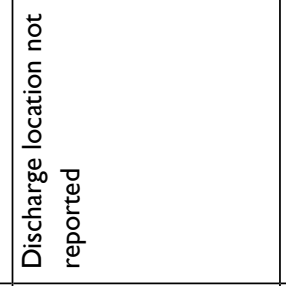 & & 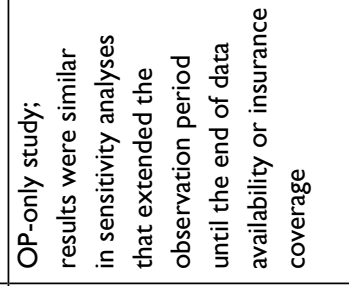 & & 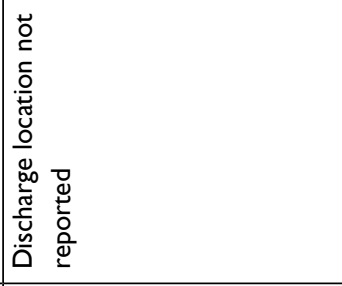 \\
\hline 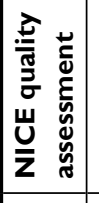 & 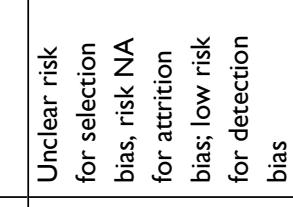 & & 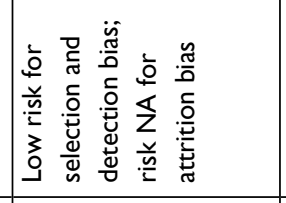 & & 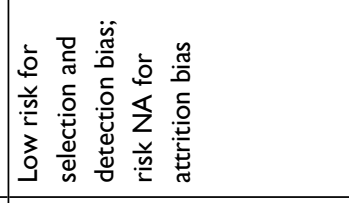 & & 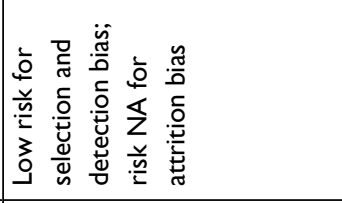 \\
\hline 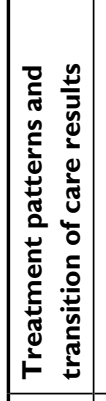 & 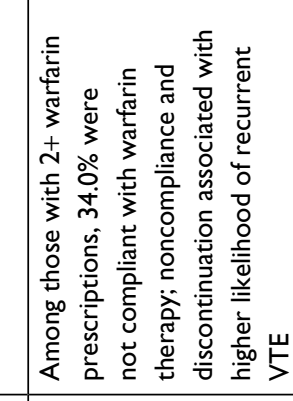 & & 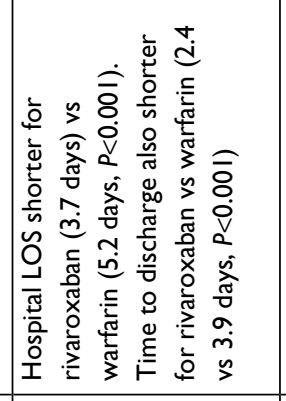 & & 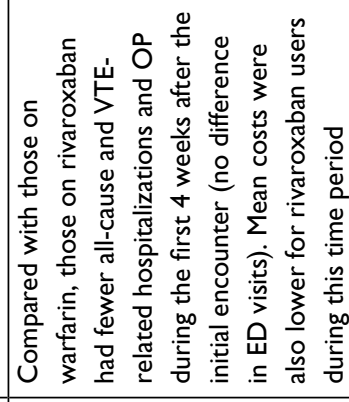 & & 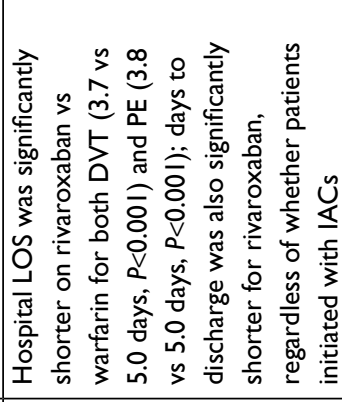 \\
\hline 苋 & 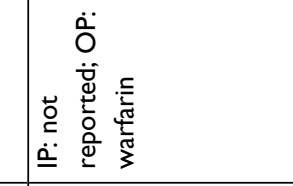 & & 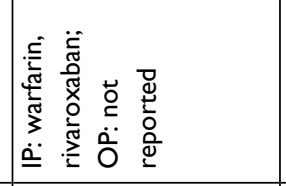 & & 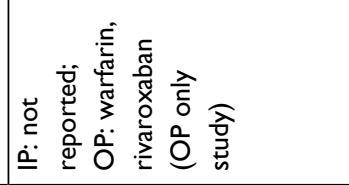 & & 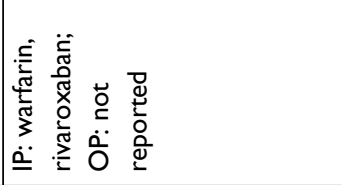 \\
\hline 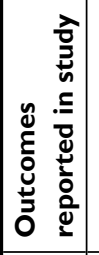 & 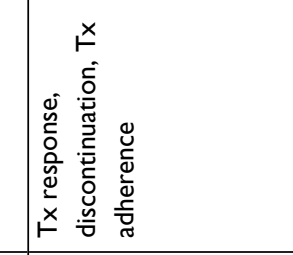 & & 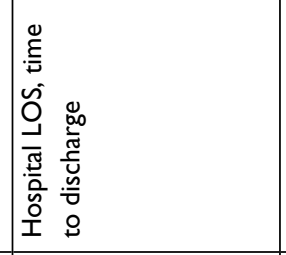 & & 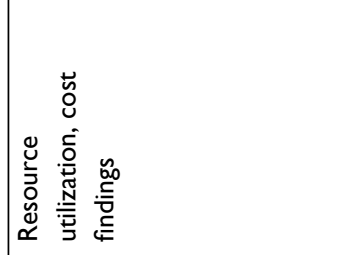 & & 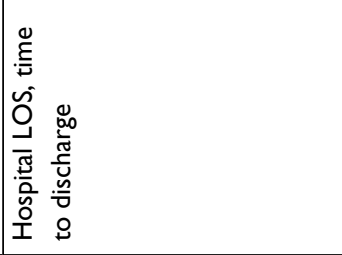 \\
\hline 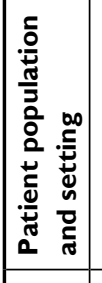 & 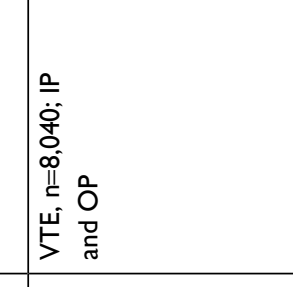 & & 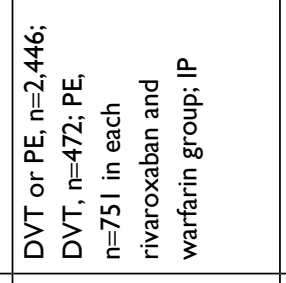 & & 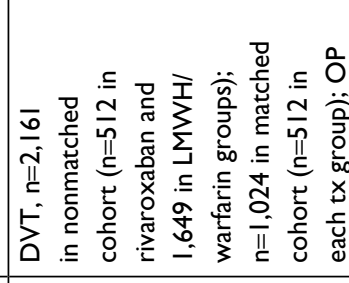 & & 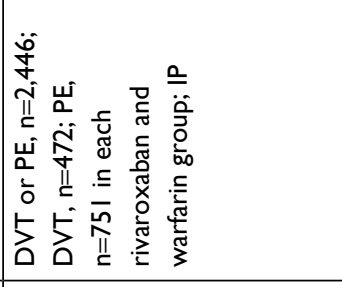 \\
\hline & 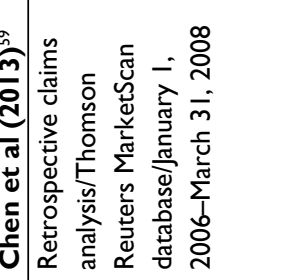 & 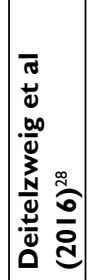 & 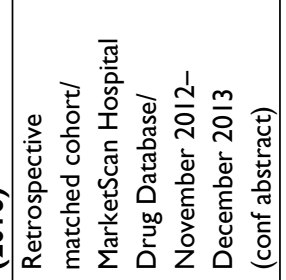 & 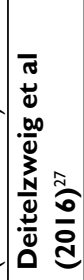 & 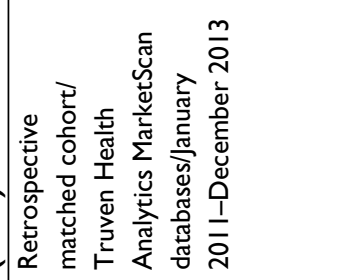 & 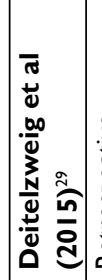 & 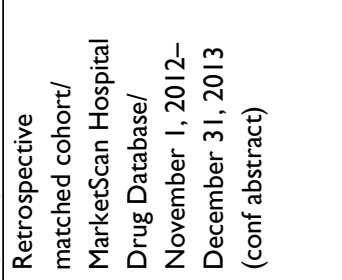 \\
\hline
\end{tabular}




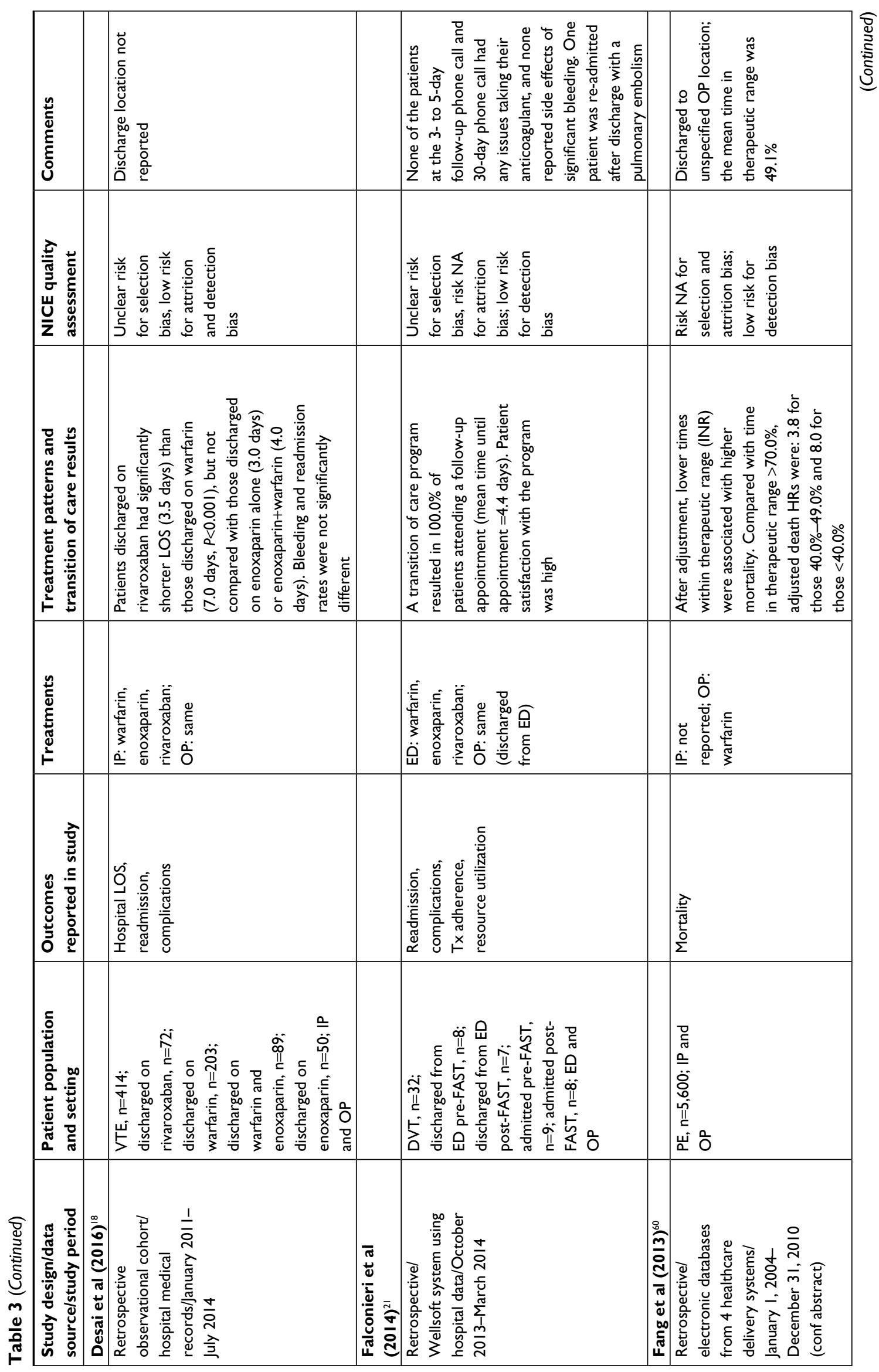




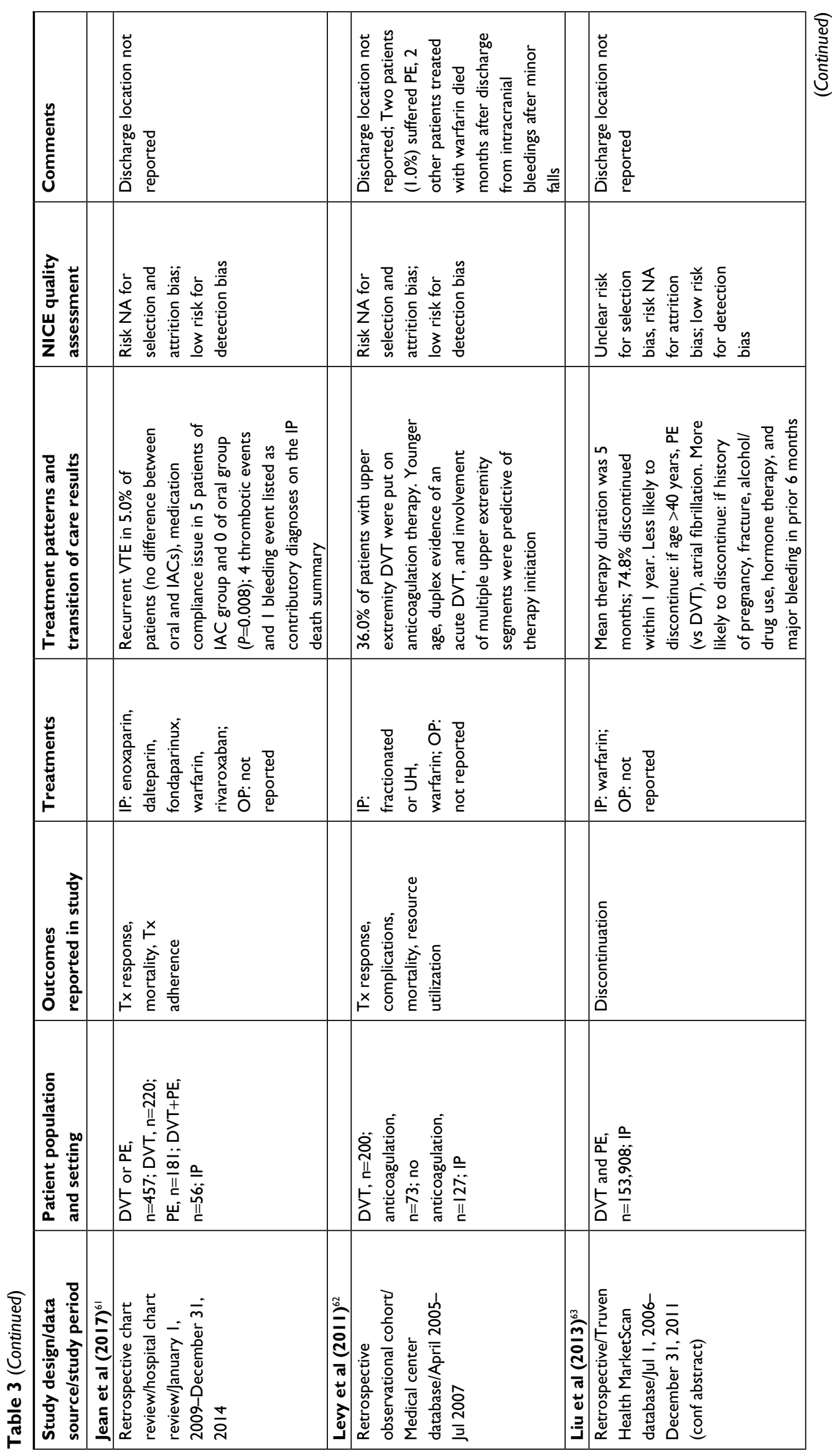




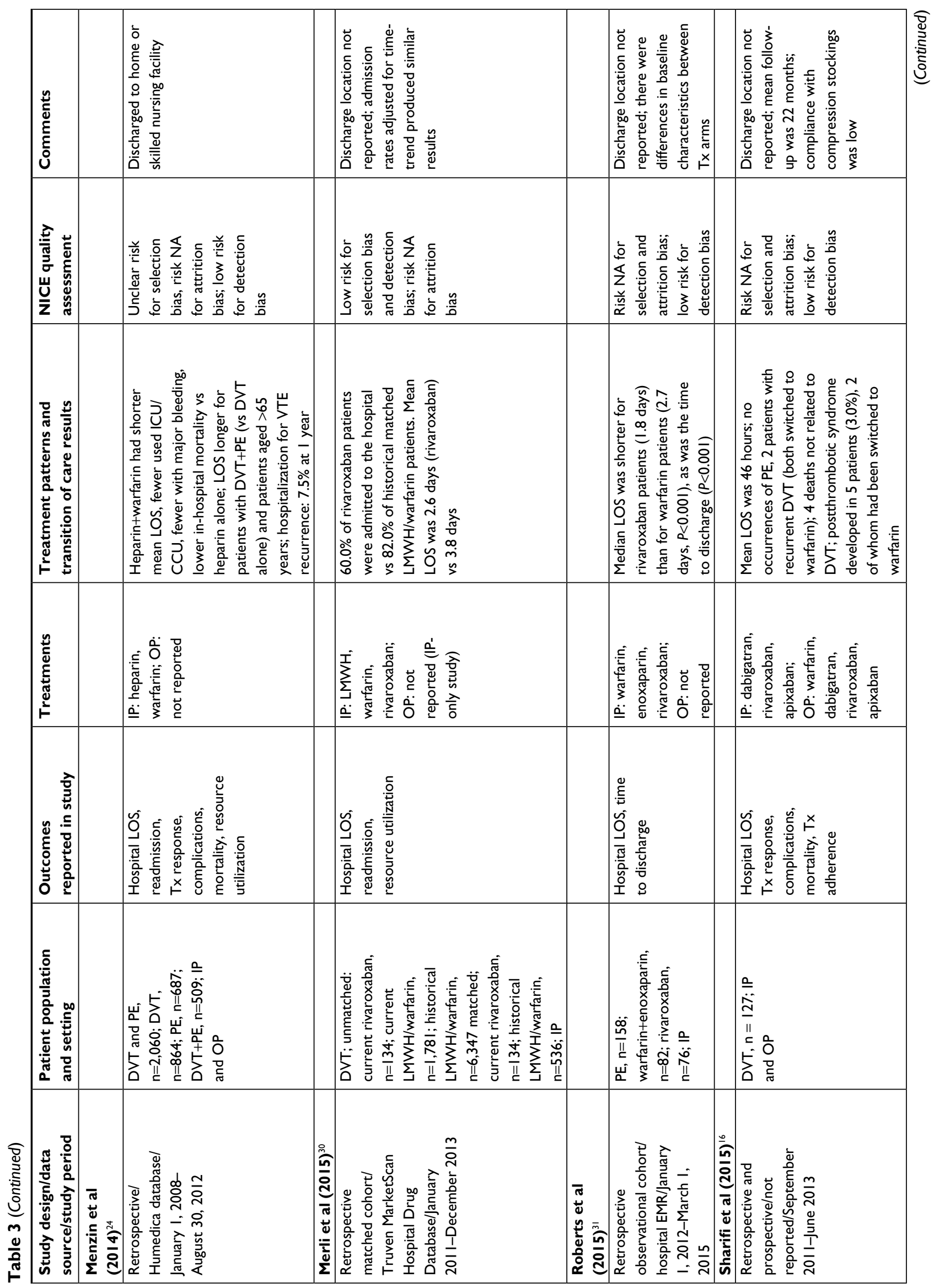




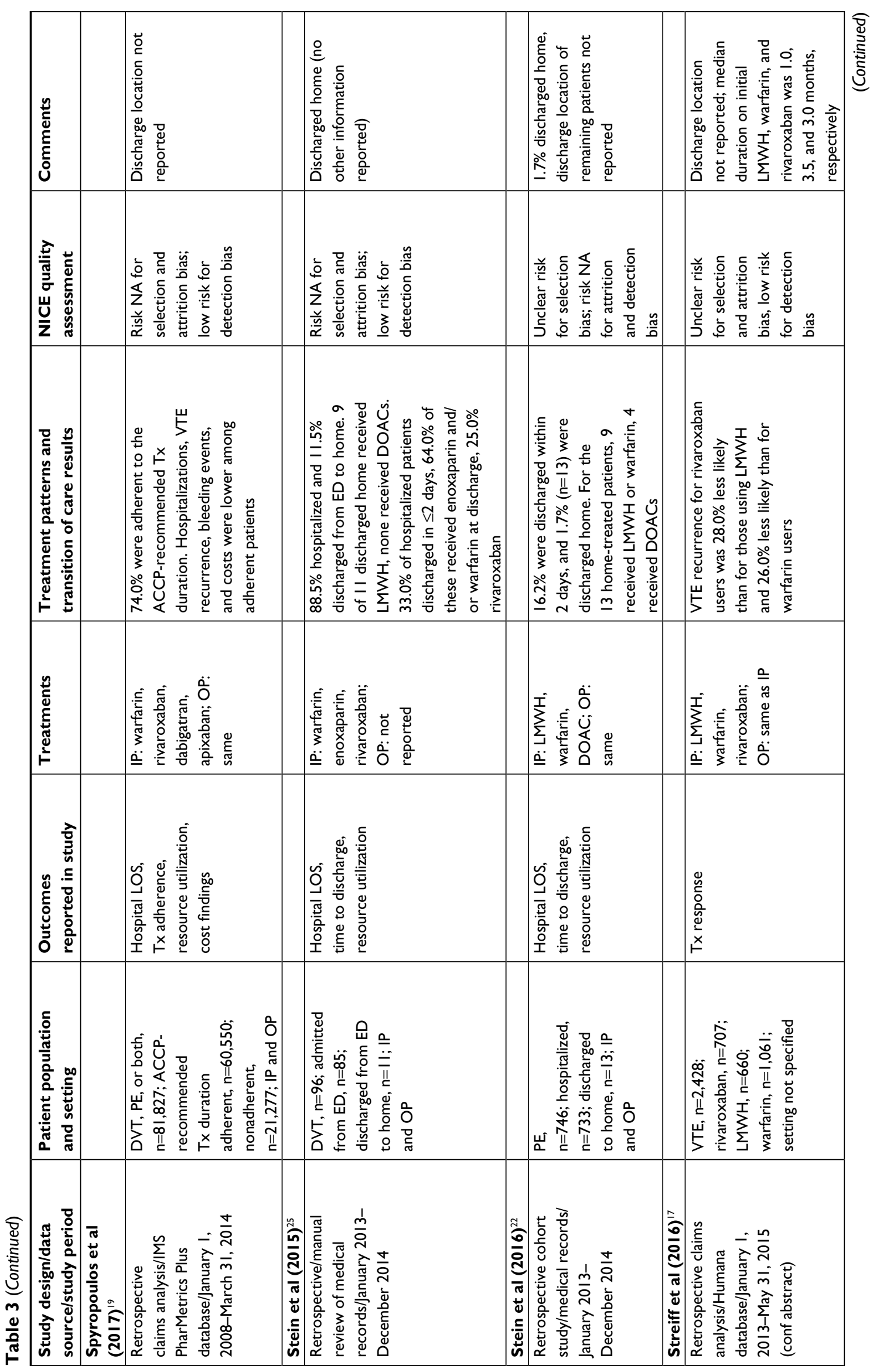




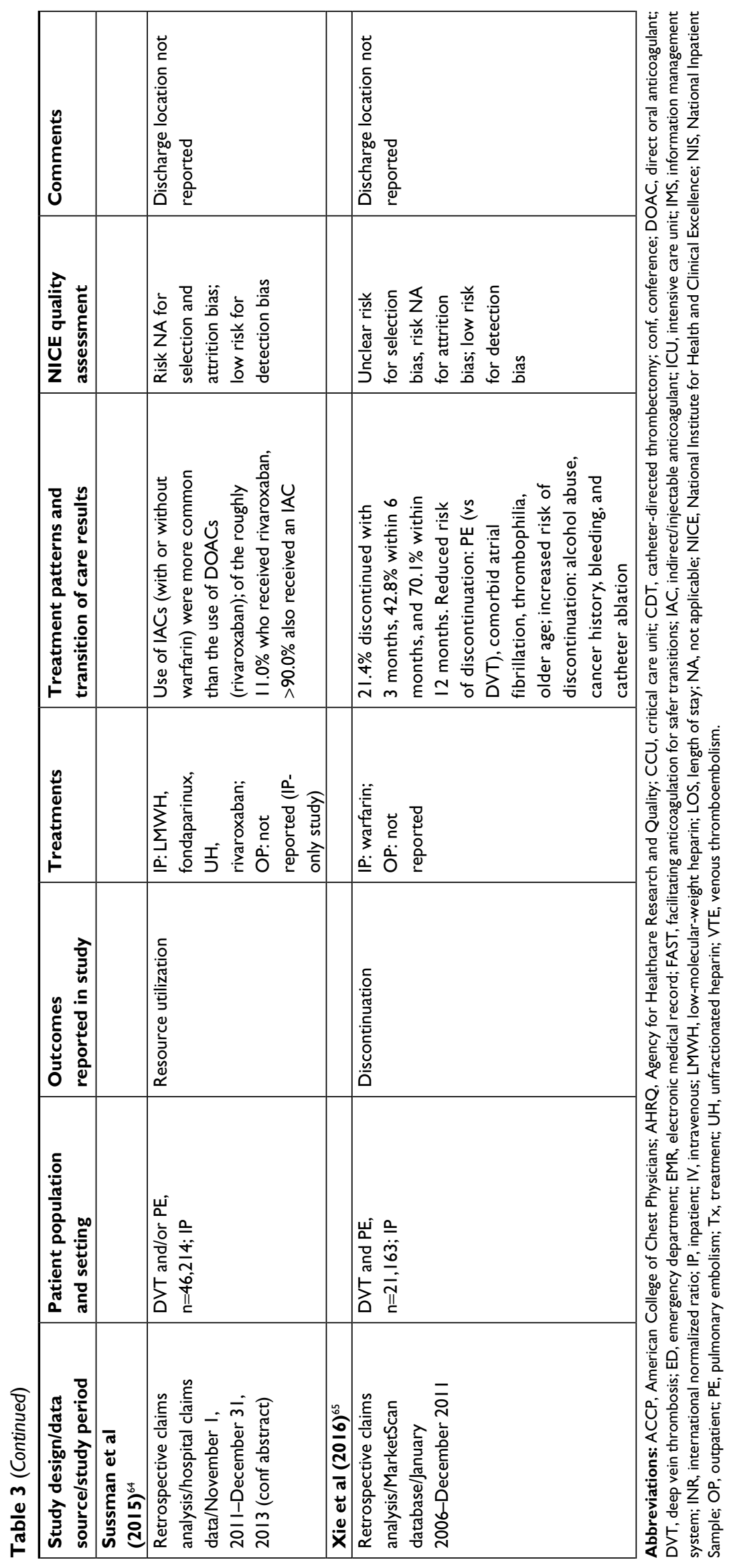




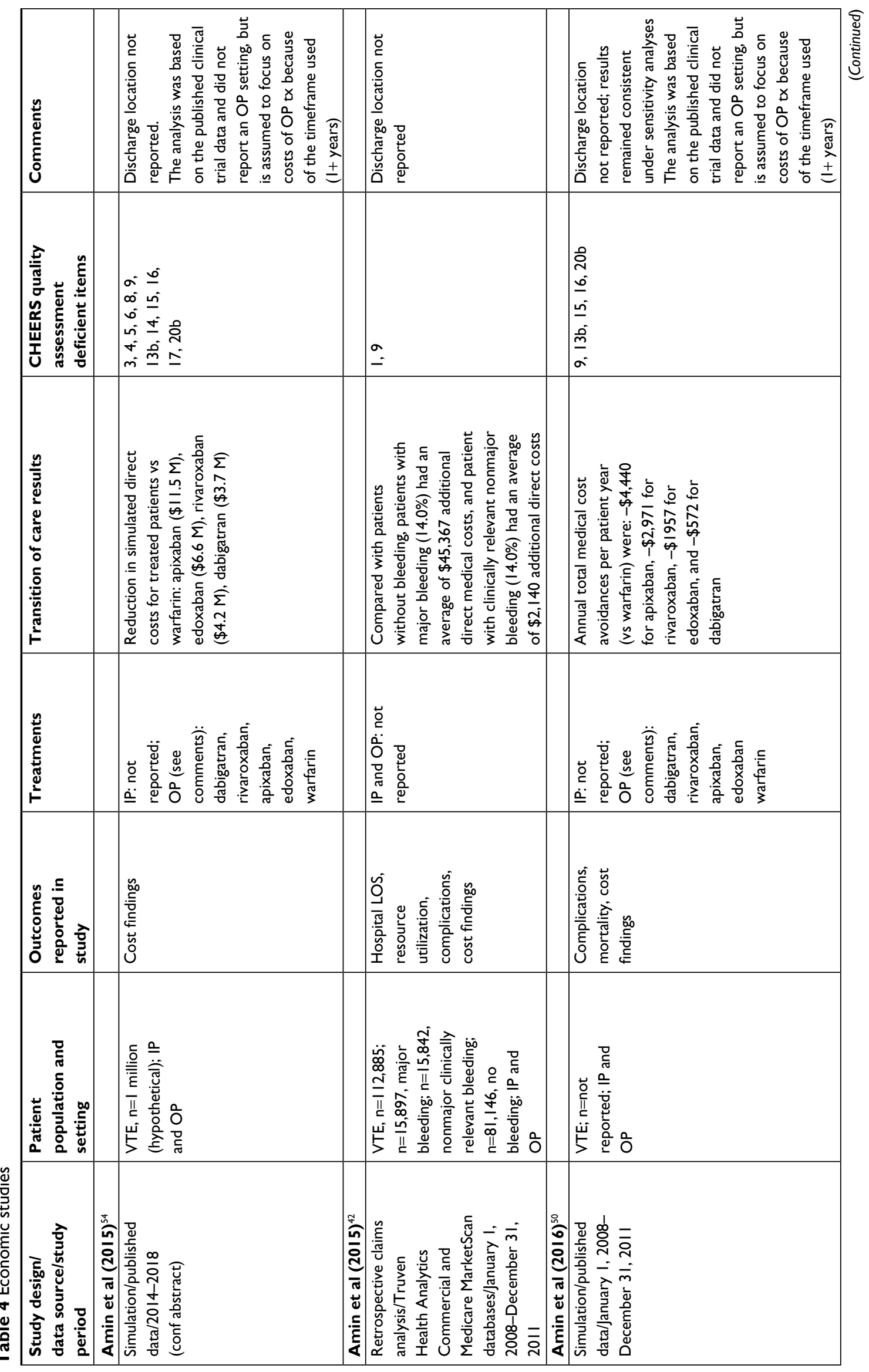




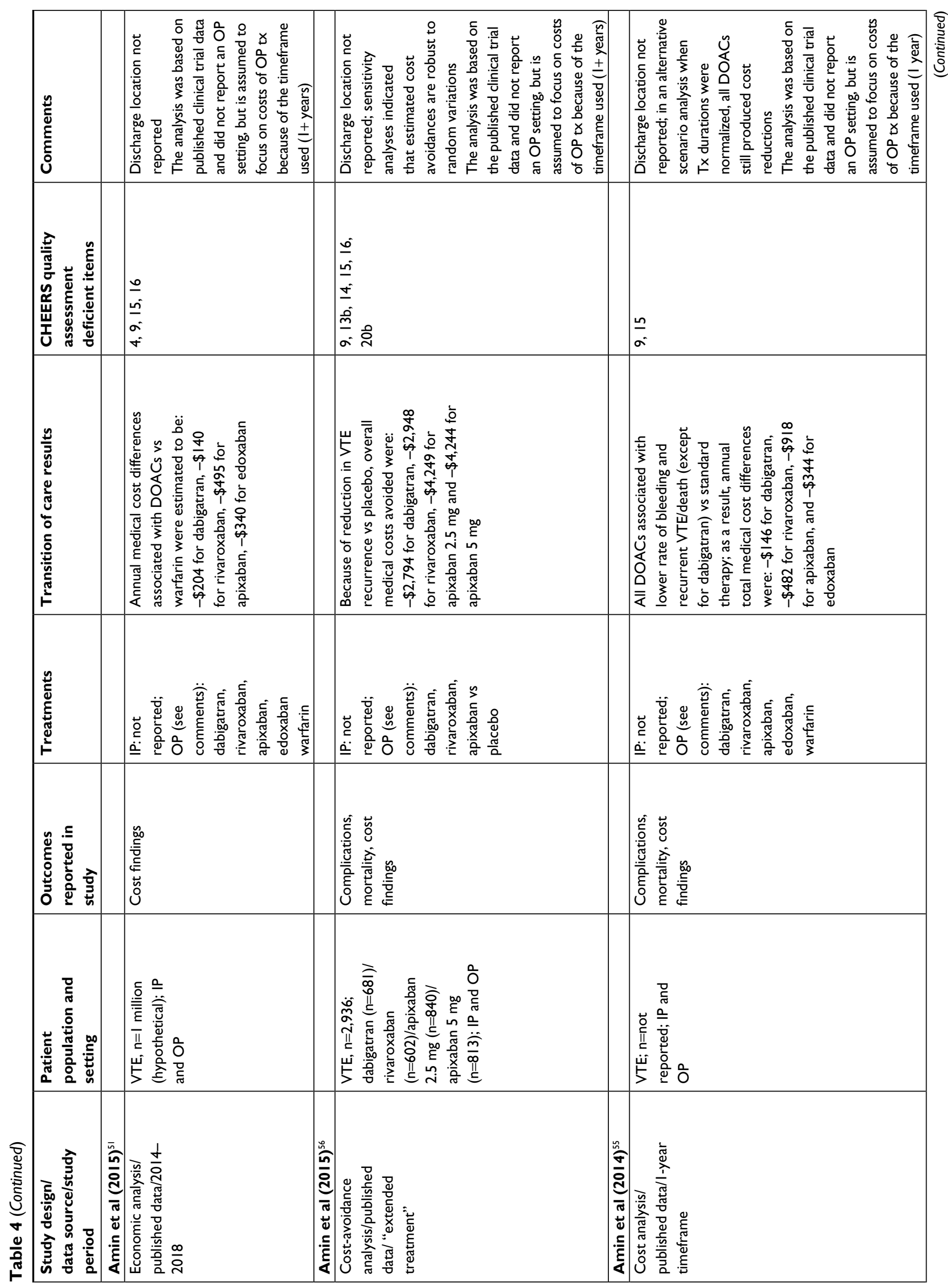




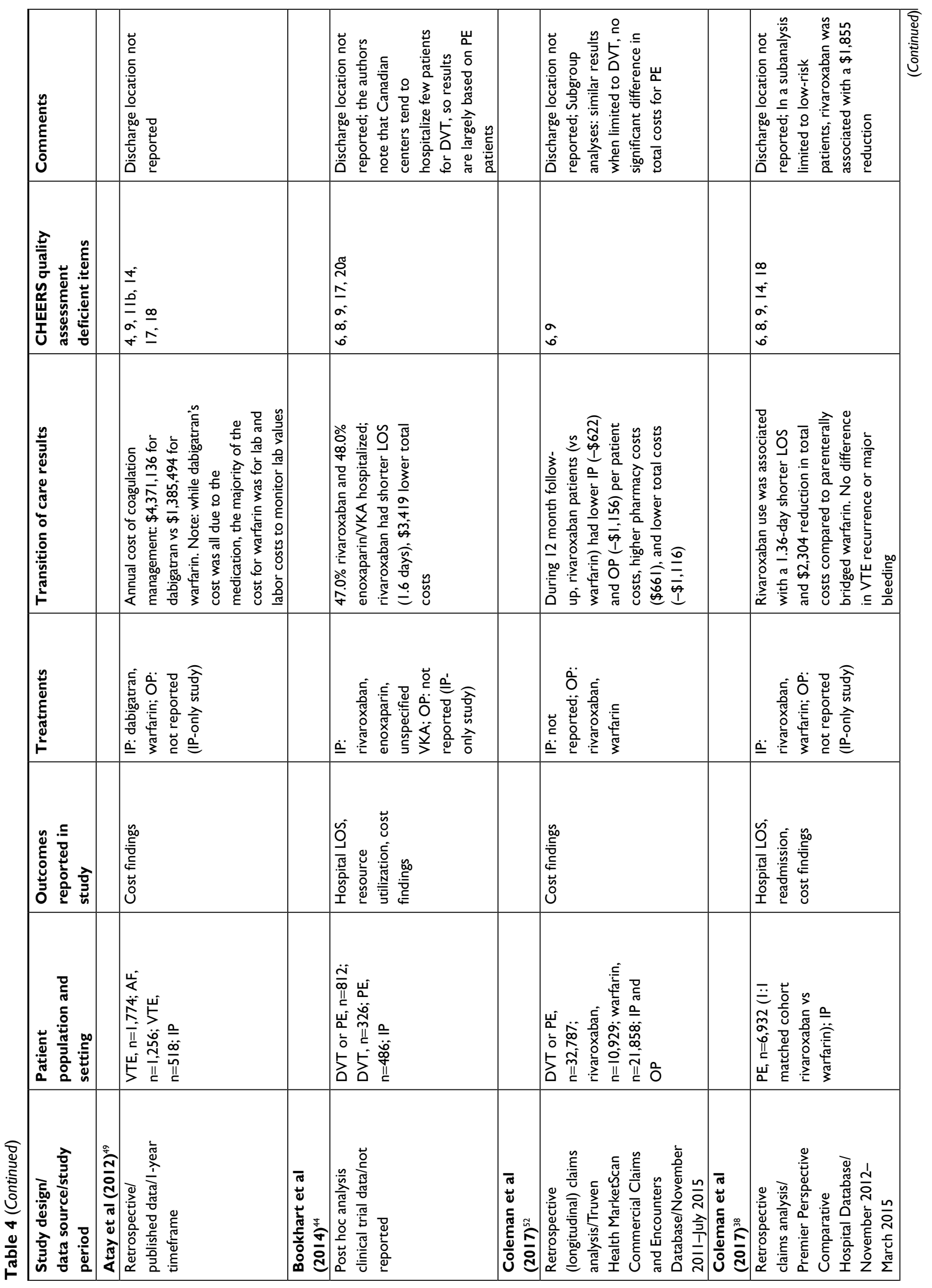




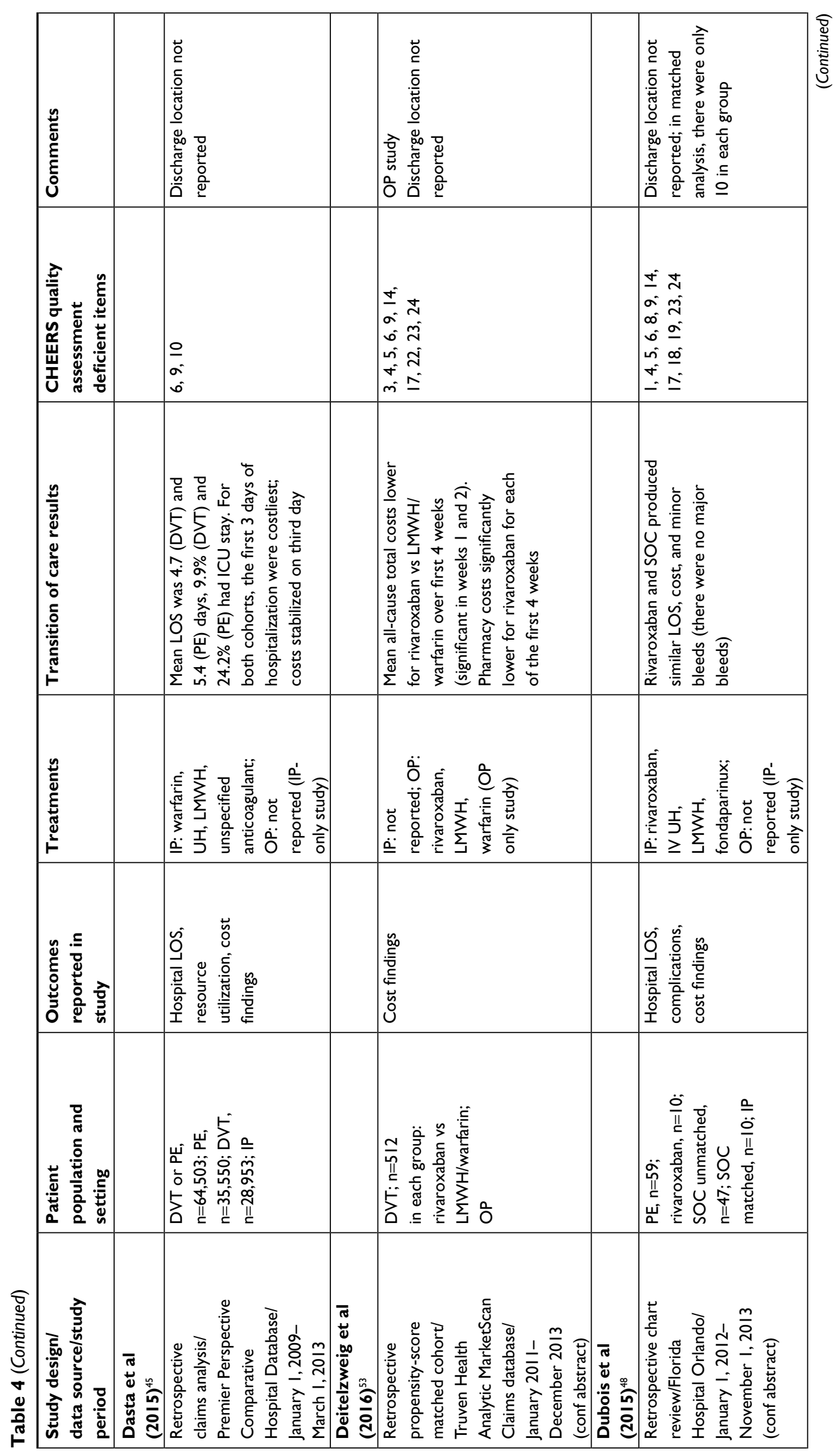




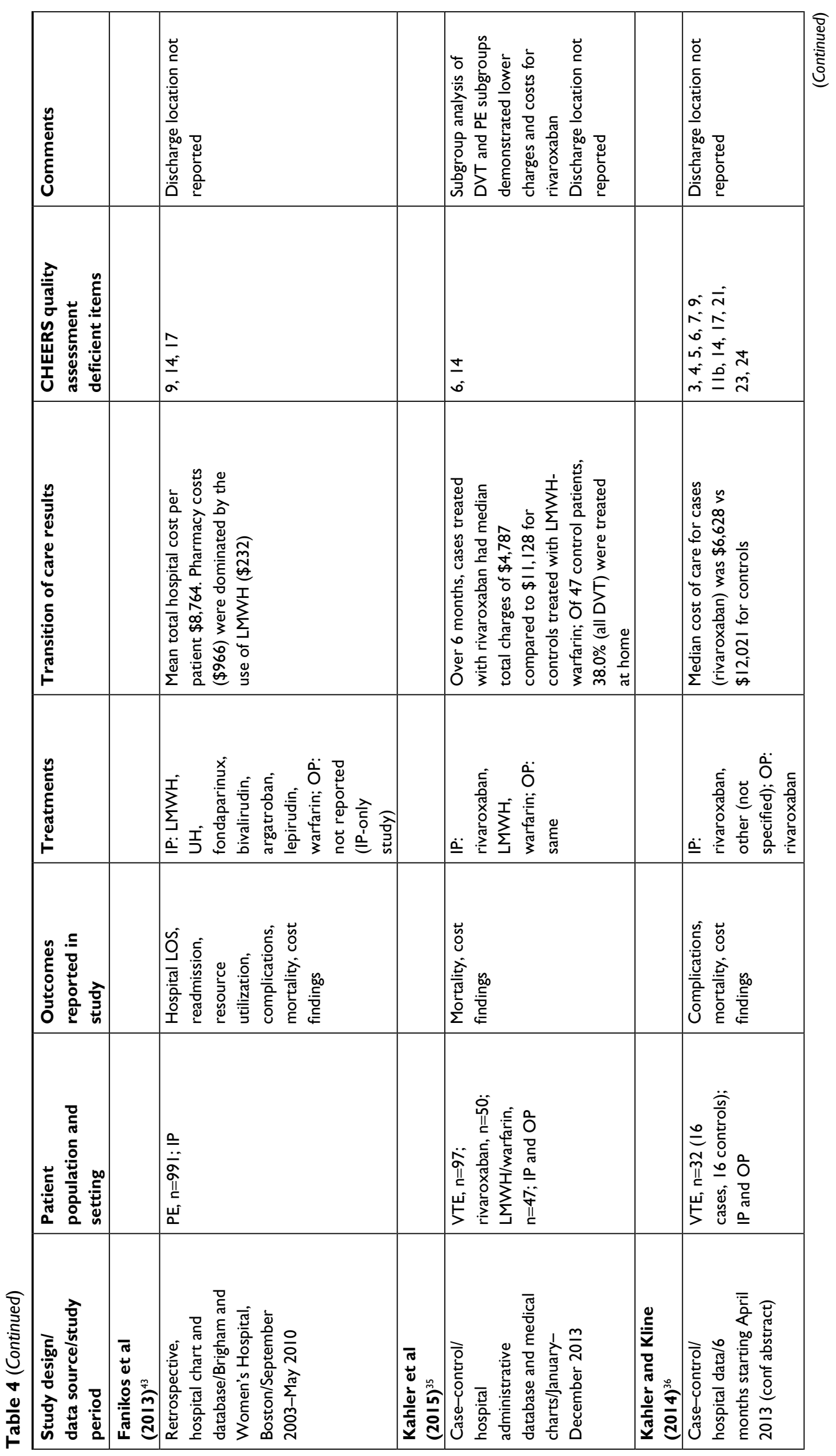




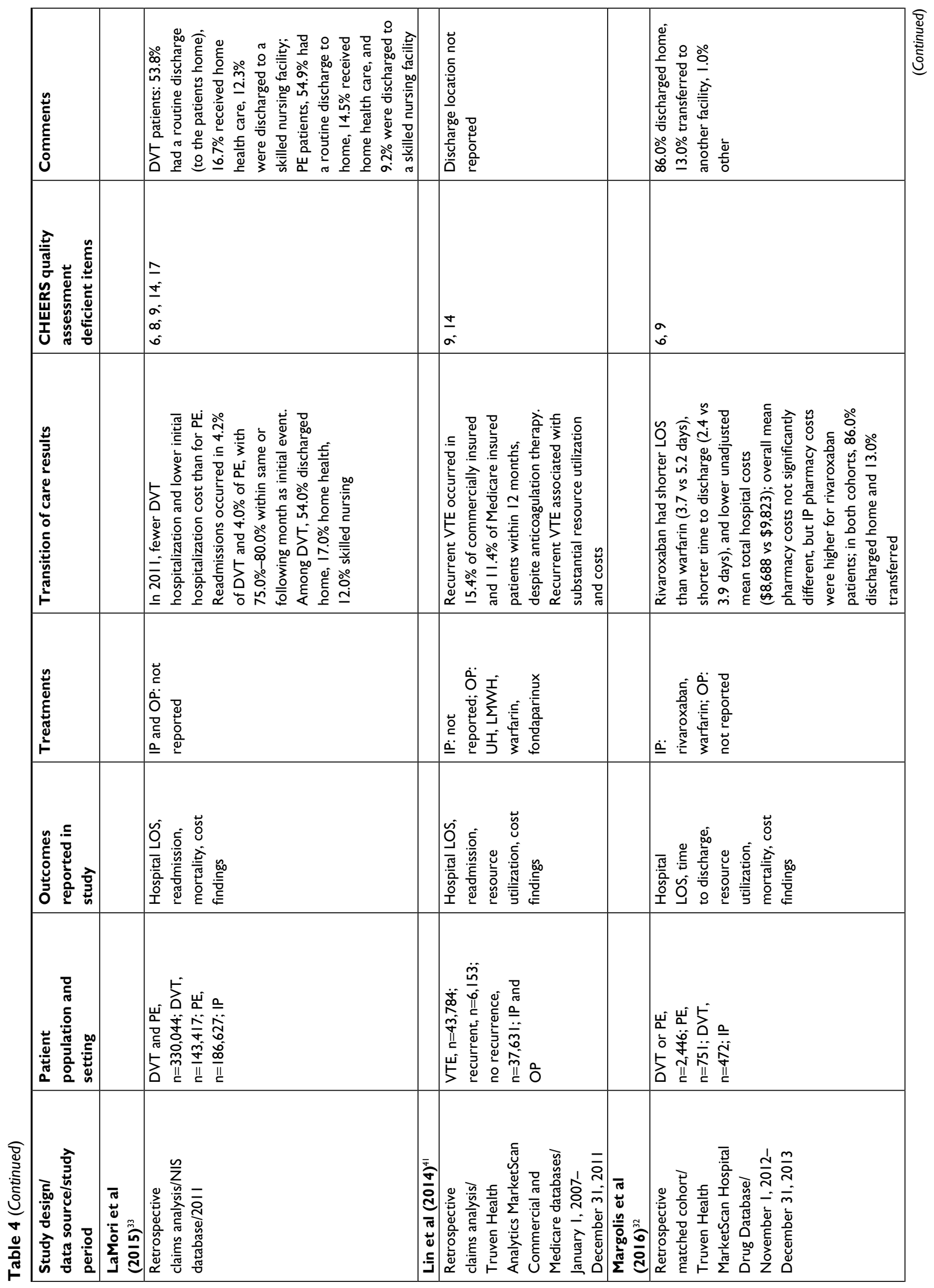




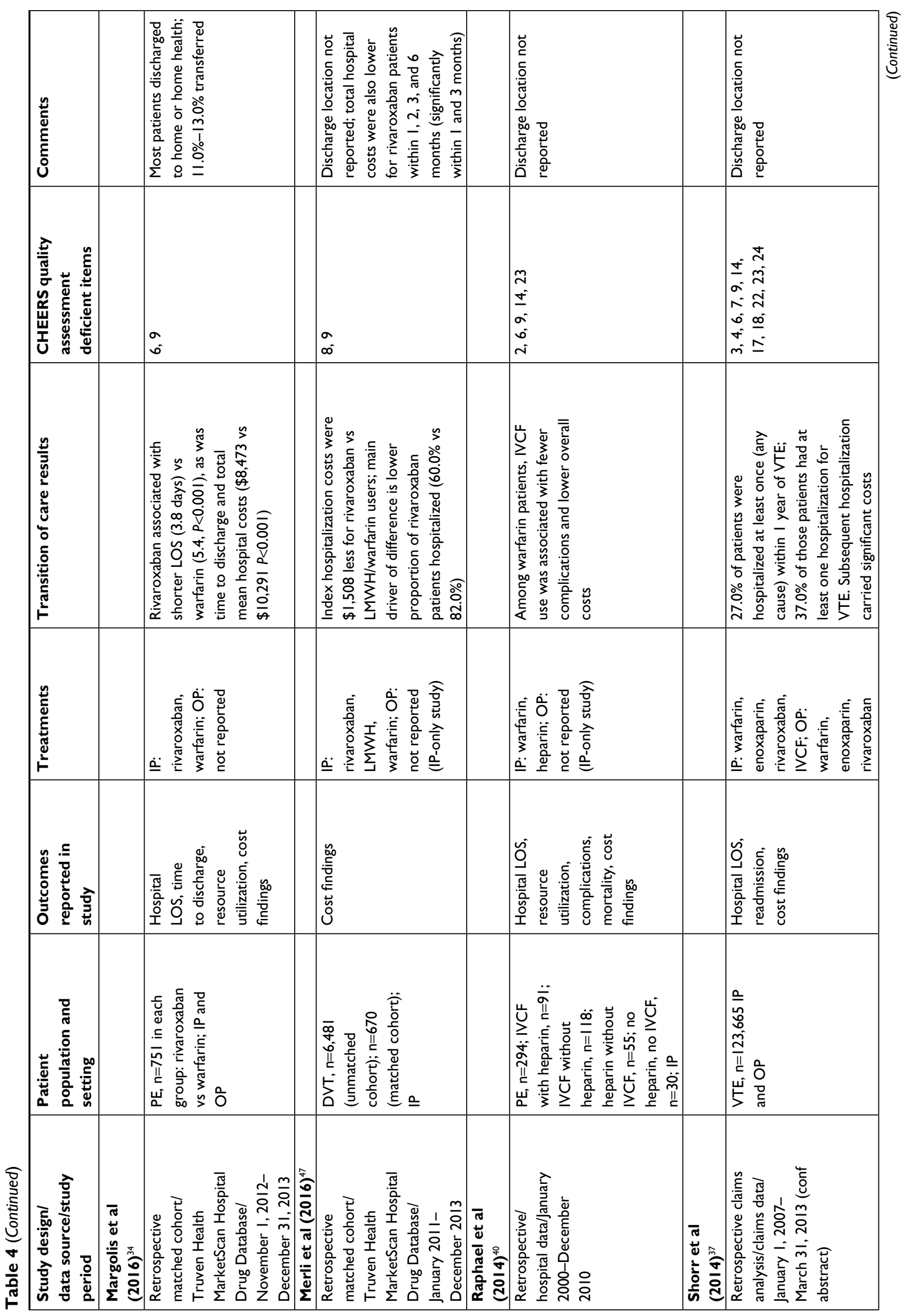




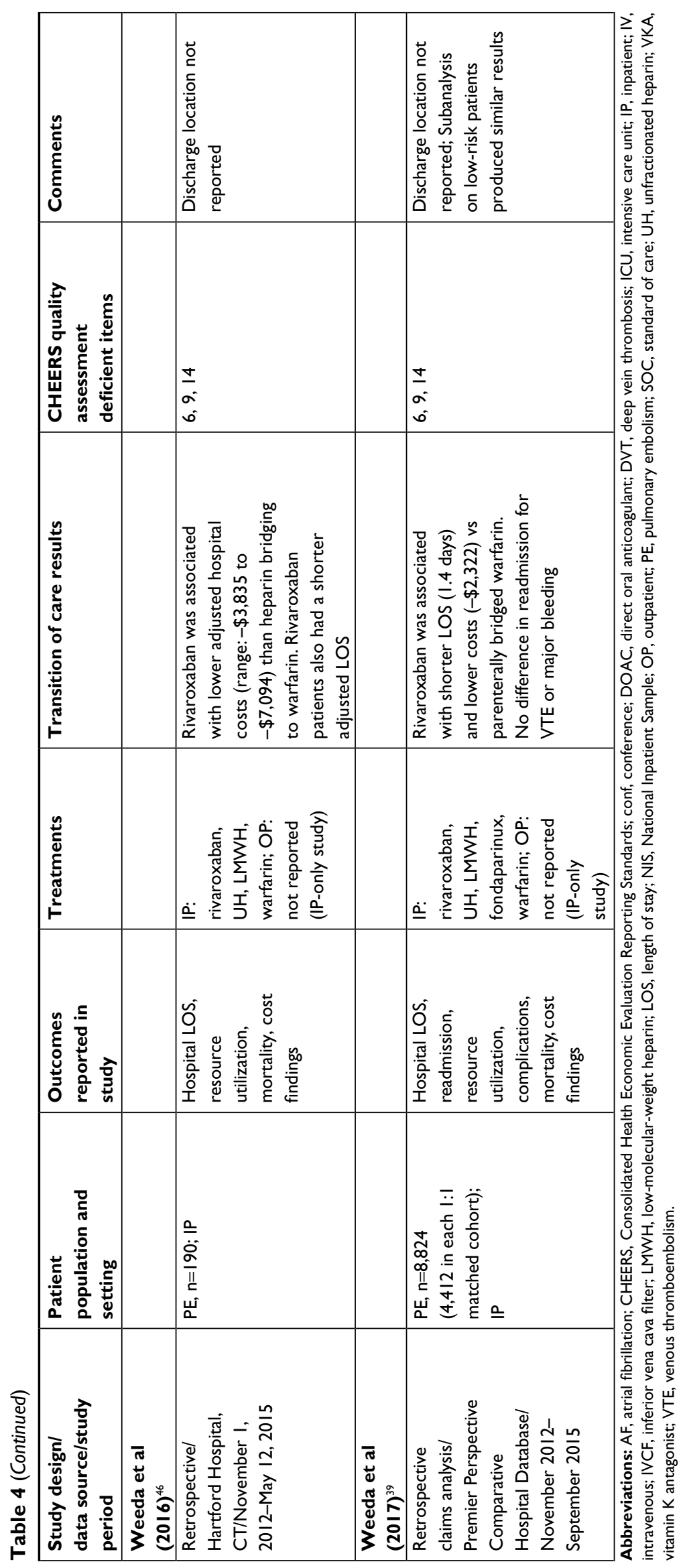


Stein et $\mathrm{al}^{25}$ assessed the prevalence of home treatment with DOACs for patients who had been hospitalized for an acute PE. They found that 13 of $746(1.7 \%)$ patients with $\mathrm{PE}$, who were not hypoxic, were stable enough for home treatment and that four of the 13 patients (30.8\%) received post-discharge DOACs with the remaining nine patients (69.2\%) receiving LMWH or warfarin. Finally, Desai et al ${ }^{18}$ compared outcomes associated with rivaroxaban, warfarin, enoxaparin, or warfarin+enoxaparin for patients hospitalized for VTE and discharged (discharge location was not reported). Patients who were discharged on rivaroxaban had a significantly shorter hospital LOS when compared with warfarin $(P<0.001)$, but not when compared with enoxaparin or warfarin+enoxaparin; also, in-hospital bleeding rates and 6-month readmission rates were not significantly different across groups.

\section{Outcomes (economic search)}

Table 4 displays the study details and findings for the 25 economic studies that were included in the review following the search on economic outcomes. Seventeen studies had a retrospective design, two studies had a case-control design, three studies were cost models, two studies were simulation models, and one study was a post hoc analysis of hospital LOS and cost data from the EINSTEIN clinical trial.

Only four economic studies reported a discharge location; three reported discharge to home or a SNF, ${ }^{32-34}$ and the fourth study ${ }^{35}$ reported that $38.0 \%$ of patients were discharged to home, but did not report the discharge location for the remaining patients. Of the 21 economic studies that did not report a discharge location, 10 were IP-only studies. Only three of the 25 economic studies reported both IP and OP treatments. ${ }^{35-37}$ All three studies reported both IP and OP DOAC, and two of the studies ${ }^{35,37}$ reported IP and OP VKA (warfarin) with either enoxaparin or LMWH.

With respect to the health care resource utilization associated with the treatment for VTE, 14 studies reported hospital LOS, six studies reported readmission rates, and 10 studies reported on other types of health care resource utilization. Eight of the 14 studies that reported hospital LOS were IPonly studies and did not report a post-discharge treatment or location. The hospital LOS for the eight IP-only studies ranged from a mean of 3.2 days for PE patients receiving rivaroxaban ${ }^{38,39}$ to a mean of 9.4 days for $\mathrm{PE}$ patients who received heparin plus an $\mathrm{IVCF}^{40}$ For the six studies that were not IP-only, ${ }^{32-34,37,41,42}$ the hospital LOS ranged from a mean of 0.2 days for VTE patients with clinically relevant nonmajor bleeding during the 1-year follow-up period (no treatment reported $)^{42}$ to 8.4 days for patients with VTE recurrence at 1 year who were receiving VKAs or IACs. ${ }^{41}$

The readmission rates for the six studies that reported readmission ranged from $1.5 \%$ within 2 months of an initial PE event, ${ }^{39}$ for patients receiving rivaroxaban, to $15.4 \%$ within a mean of 74 days from an initial VTE event, ${ }^{41}$ for patients receiving VKAs or IACs. Three of the remaining four studies had readmission rates $\leq 4 \% \%^{33,38,43}$ within a period of $2-3$ months following an initial event, and the final study ${ }^{37}$ had a readmission rate of $10.1 \%$ within 284 days of an initial VTE event for patients receiving DOACs, VKAs, or IACs. The other types of health care resource utilization that were reported included hospital and/or intensive care unit (ICU) stay, ${ }^{34,44,45}$ OP and/or ED visits, ${ }^{41,42}$ treatment of additional thrombotic events, ${ }^{39,46}$ diagnostic procedures, ${ }^{43}$ time from admission to first treatment dose, ${ }^{32}$ and placement of an IVCF. ${ }^{40}$

With respect to direct and indirect costs associated with treatment for VTE, all 25 studies reported direct costs and none of the studies reported indirect costs. Ten studies were IP-only studies that focused on the cost of hospitalization. Five of the 10 studies $^{38,39,44,46,47}$ found a shorter LOS and lower hospital costs for rivaroxaban vs parenterally bridged warfarin for treating PE or DVT, and a sixth study ${ }^{48}$ compared rivaroxaban to a standard of care and found no significant differences in hospital costs (study reported as a conference abstract). A seventh study ${ }^{49}$ found higher costs with dabigatran vs warfarin when treating hospitalized VTE patients, and an eighth study ${ }^{40}$ found lower hospital costs for IVCF plus heparin vs heparin alone to treat a PE within 90 days of joint replacement surgery. The remaining two studies evaluated hospital costs based on disease rather than treatment type and found the highest hospital costs in the first 3 days following an acute DVT $(\$ 1,594)$ or PE event $(\$ 1,735)^{45}$ or found that nursing cost $(\$ 5,102)$ was the largest component of mean total hospitalization costs of $\$ 8,764$ for treating PE between 2003 and $2010 .^{43}$

For the 15 economic studies that were not IP only, 10 studies $^{32,34-36,50-55}$ found significantly lower costs for various DOACs vs warfarin, and one study ${ }^{56}$ compared four DOACs (rivaroxaban, apixaban, dabigatran, and edoxaban) to placebo for extended treatment of VTE and found the lowest overall medical costs avoided was for dabigatran. The remaining four studies ${ }^{33,37,41,42}$ did not compare costs based on the treatment.

\section{Discussion}

The objectives of this review were to summarize evidence on VTE treatment patterns in IP and OP settings and to deter- 
mine discharge location after patients leave the IP setting. This review further sought to examine patient outcomes, resource utilization, and costs associated with VTE patients transitioning from one setting to the next. We were able to determine that patients used DOACs, LMWH, and warfarin in IP and OP settings. However, given the data available, it was unclear whether patients continued using the therapies prescribed as they moved from one setting to the next or if they were switched to a different therapy after leaving the IP setting. In short, our ability to report on treatment patterns during the transition from IP to OP status was constrained by the fact that only eight clinical studies and three economic studies reported both IP and OP treatments.

It is encouraging to see that within IP and OP settings, physicians are prescribing according to the CHEST guidelines for antithrombotic therapy in VTE. ${ }^{4}$ Note that this simply means we are not seeing prescription of medication outside the class of "anticoagulant" or "antiplatelet," but our observation does not speak to the manner in which antithrombotics are being prescribed. For example, for VTE without a cancer diagnosis, it is suggested that DOACs be prescribed over VKAs and LMWH; on the other hand, for VTE with a cancer diagnosis, LMWH is recommended over the other therapies. With respect to the CHEST guidelines, there are other recommendations that go into specific detail about which antithrombotic therapy to use for different VTE cases. However, it should be noted that our study was not directed at delving into those specific details. Our main concern was finding out which treatments patients received within IP and OP care settings, the locations to where patients were discharged, and what treatment regimen, if any, they received post-discharge.

As part of the objective, we wanted to look at patient discharge location following release from the IP setting, but only a limited number of studies reported on discharge location. This could be explained by our finding that $78 \%$ of the identified studies were retrospective in nature and the majority of these studies $(73.7 \%)$ were based on administrative claims data, which do not typically include information about discharge location. For the 11 studies that reported discharge, nine reported discharge for the most part to the home and to a lesser extent, SNFs, and two studies reported discharge to a nonspecified location. What would be interesting to examine is whether discharge to home was further broken down by strategy for care - for example, use of caregiver or self-care. We say this because specific discharge location - home or SNF - and strategy for care generally inform how acute or severe the VTE episode may have been. ${ }^{57}$

With respect to patient outcomes, several studies in this literature review found that DOACs were associated with shorter hospital LOS and lower costs when compared with warfarin. When examining health care resource utilization, six economic studies reported readmission rates that ranged from $1.5 \%$ for patients receiving rivaroxaban to $15.4 \%$ for patients receiving a VKA or IAC. The more notable gaps in the literature include the finding that none of the studies reported indirect costs such as work productivity. More studies are needed that examine VTE treatments when patients are transitioning from IP to OP settings and their associated outcomes including work productivity. Of note, is a study conducted by Stein et $\mathrm{al}^{22}$ who examined the prevalence of using DOACs to treat patients with PE who were discharged from an emergency room to home and found that only four of the 13 patients with stable PE who were eligible to receive post-discharge DOACs actually received them. The authors did not report whether the decision to use a post-discharge DOAC was made by the clinician or may have been partly determined by the patient. The only study that surveyed patients about satisfaction with treatment and the process of transitioning care to an OP setting ${ }^{21}$ did not examine patient satisfaction based on specific treatments such as DOACs vs VKAs - most likely because of the small sample size $(n=6)$. More studies are needed that examine a patient's satisfaction with the treatment received during transition from IP to OP settings.

All literature reviews are limited by publication bias with respect to the articles that are available at the time that a search is conducted. Also, the articles in this review are published in English and publication constraints were placed on articles identified by the search with studies limited to those published 2011-2016. Also, 78.0\% of all study designs were retrospective and $35.0 \%$ of all studies were IP only, which limits our ability to make statements about VTE treatment patterns as patients transition from IP to OP settings or what the post-discharge locations were.

\section{Conclusion}

Only a small number of studies were found that reported and/ or characterized IP and OP treatments for VTE, discharge location, and outcomes. For the studies that did report this information, DOACs were associated with shorter LOS, lower costs, and better patient outcomes (eg, VTE recurrence) vs VKAs; however, one study reported that DOACs are not being utilized for eligible patients with stable VTE who are discharged to home. Although a small number of transition of care studies were found in this review that reported both IP and OP treatments and discharge location, the information contained in these studies may identify opportunities to improve the management of VTE through coordination 
of treatment and care or may help inform decisions about VTE patients as they transition from inpatient or ED to post-discharge care.

\section{Abbreviations}

CHEERS, Consolidated Health Economic Evaluation Reporting Standards; DOAC, direct oral anticoagulant; DVT, deep vein thrombosis; ED, emergency department; IAC, injectable anticoagulant; ICU, intensive care unit; IP, inpatient; IVCF, inferior vena cava filter; LMWH, low-molecular-weight heparin; LOS, length of stay; MeSH, Medical Subject Heading; NICE, National Institute for Health and Clinical Excellence; OP, outpatient; PE, pulmonary embolism; RCT, randomized control trial; SNF, skilled nursing facility; VKA, vitamin $\mathrm{K}$ antagonist; VTE, venous thromboembolism

\section{Acknowledgment}

This study was supported by Pfizer Inc. and Bristol-Myers Squibb (BMS), who contracted with Optum Inc. to conduct the study and develop the manuscript.

\section{Author contributions}

All authors were involved in the conception and design, interpreting data, and writing and editing the manuscript. In addition, Virginia M Rosen was involved in data collection and analysis. All authors gave final approval of the version to be published, and agree to be accountable for all aspects of the work.

\section{Disclosure}

Virginia M Rosen is an employee of Optum, Inc. who was a paid consultant to Pfizer and BMS in connection with the collection and analysis of the data and development of this manuscript. The authors report no other conflicts of interest in this work.

\section{References}

1. Deitelzweig SB, Johnson BH, Lin J, Schulman KL. Prevalence of clinical venous thromboembolism in the USA: current trends and future projections. Am J Hematol. 2011;86(2):217-220.

2. Centers for Disease Control and Prevention (CDC). Venous thromboembolism in adult hospitalizations - United States, 2007-2009. MMWR Morb Mortal Wkly Rep. 2012;61(22):401-404.

3. Grosse SD, Nelson RE, Nyarko KA, Richardson LC, Raskob GE. The economic burden of incident venous thromboembolism in the United States: a review of estimated attributable healthcare costs. Thromb Res. 2016;137:3-10.

4. Kearon C, Akl EA, Ornelas J, et al. Antithrombotic therapy for VTE disease: CHEST guideline and expert panel report. Chest. 2016;149(2):315-352.

5. Schulman S, Kearon C, Kakkar AK, et al. Dabigatran versus warfarin in the treatment of acute venous thromboembolism. $N$ Engl $J$ Med. 2009;361(24):2342-2352.
6. EINSTEIN Investigators, Bauersachs R, Berkowitz SD, et al. Oral rivaroxaban for symptomatic venous thromboembolism. NEngl J Med. 2010;363(26):2499-2510.

7. Agnelli G, Buller HR, Cohen A, et al. Oral apixaban for the treatment of acute venous thromboembolism. NEngl J Med. 2013;369(9):799-808.

8. Lenchus JD. Transitions in the prophylaxis, treatment and care of patients with venous thromboembolism. Adv Ther. 2016;33(1):29-45.

9. Padron M, Miyares MA. Development of an anticoagulation stewardship program at a large tertiary care academic institution. J Pharm Pract. 2015;28(1):93-98.

10. Brock J, Mitchell J, Irby K, et al. Association between quality improvement for care transitions in communities and rehospitalizations among Medicare beneficiaries. JAMA. 2013;309(4):381-391.

11. Owens GM, Fine C, Harrington DW, et al. Improving transitions of care for patients with thromboembolic disease. Am J Manag Care. 2014;20(4 Suppl):S81-91.

12. Moher D, Liberati A, Tetzlaff J, Altman DG, PRISMA Group. Preferred reporting items for systematic reviews and meta-analyses: the PRISMA statement. PLoS Med. 2009;6(7):e1000097.

13. Liberati A, Altman DG, Tetzlaff J, et al. The PRISMA statement for reporting systematic reviews and meta-analyses of studies that evaluate health care interventions: explanation and elaboration. PLoS Med. 2009;6(7):e1000100.

14. National Institute for Health and Clinical Excellence [homepage on the Internet]. The Guidelines Manual. London: National Institute for Health and Clinical Excellence; 2009. www.nice.org.uk. Accessed November 23, 2018.

15. Husereau D, Drummond M, Petrou S, et al. Consolidated Health Economic Evaluation Reporting Standards (CHEERS)-explanation and elaboration: a report of the ISPOR Health Economic Evaluation Publication Guidelines Good Reporting Practices Task Force. Value Health. 2013;16(2):231-250.

16. Sharifi M, Freeman W, Bay C, Sharifi M, Schwartz F. Low incidence of post-thrombotic syndrome in patients treated with new oral anticoagulants and percutaneous endovenous intervention for lower extremity deep venous thrombosis. Vasc Med. 2015;20(2):112-116.

17. Streiff MB, Milentijevic D, Mccrae K, et al. Recurrent VTE in cancer patients treated with anticoagulation. Journal of Clinical Oncology. 2016;34(15_suppl):10024-10024.

18. Desai A, Desai A, Calixte R, et al. Comparing Length of Stay Between Patients Taking Rivaroxaban and Conventional Anticoagulants for Treatment of Venous Thromboembolism. Lung. 2016;194(4): 605-611.

19. Spyropoulos AC, Preblick R, Kwong WJ, Lingohr-Smith M, Lin J. Is adherence to the American College of Chest Physicians recommended anticoagulation treatment duration associated with different outcomes among patients with venous thromboembolism? Clin Appl Thromb Hemost. 2017;23(6):532-541.

20. Beam DM, Kahler ZP, Kline JA. Immediate discharge and home treatment with rivaroxaban of low-risk venous thromboembolism diagnosed in two U.S. emergency departments: a one-year preplanned analysis. Acad Emerg Med. 2015;22(7):788-795.

21. Falconieri L, Thomson L, Oettinger G, et al. Facilitating anticoagulation for safer transitions: preliminary outcomes from an emergency department deep vein thrombosis discharge program. Hosp Pract. 2014;42(4):16-45.

22. Stein PD, Matta F, Hughes PG, et al. Home Treatment of pulmonary embolism in the era of novel oral anticoagulants. Am J Med. 2016;129(9):974-977.

23. Cefalo P, Weinberg I, Hawkins BM, et al. A comparison of patients diagnosed with pulmonary embolism who are $\geq 65$ years with patients $<65$ years. Am J Cardiol. 2015;115(5):681-686.

24. Menzin J, Preblick R, Friedman M, Menzin J, Frean M, Jacqueline Kwong W. Treatment patterns and outcomes among hospitalized patients with venous thromboembolism in the United States: an analysis of electronic health records data. Hosp Pract. 2014;42(4):59-74. 
25. Stein PD, Matta F, Hughes PG, et al. Home treatment of deep venous thrombosis in the era of new oral anticoagulants. Clin Appl Thromb Hemost. 2015;21(8):729-732.

26. Cai J, Preblick R, Zhang Q, Kwong WJ. Utilization of parenteral anticoagulants and warfarin: impact on the risk of venous thromboembolism recurrence in the outpatient setting. Am Health Drug Benefits. 2014;7(8):444-451.

27. Deitelzweig S, Laliberté F, Crivera C, et al. Hospitalizations and other health care resource utilization among patients with deep vein thrombosis treated with rivaroxaban versus low-molecular-weight heparin and warfarin in the outpatient setting. Clin Ther. 2016;38(8):e1803:1803-1816.

28. Deitelzweig S, Kline J, Margolis JM, et al. Comparison of rivaroxaban or warfarin use for venous thromboembolism on inpatient length of stay. J Am Coll Cardiol. 2065;2016;67(13 Supplement).

29. Deitelzweig S, Raut MK, Margolis J, et al. Hospital length of stay for deep vein thrombosis or pulmonary embolism among patients receiving rivaroxaban or warfarin. 20-25 June 2015, Toronto, ON, Canada. Journal of Thrombosis and Haemostasis. Conference: 25th Congress of the International Society on Thrombosis and Haemostasis, ISTH 2015.

30. Merli GJ, Hollander JE, Lefebvre P, et al. Rates of hospitalization among patients with deep vein thrombosis before and after the introduction of rivaroxaban. Hosp Pract. 2015;43(2):85-93.

31. Roberts KM, Knight TB, Padilla-Tolentino E, Murthy M, Peterson EJ. Length of stay comparison between rivaroxaban and warfarin in the treatment of pulmonary embolism: results from a real-world observational cohort study. Thrombosis. 2015;2015:1-6.

32. Margolis JM, Deitelzweig S, Kline J, et al. Shorter hospital stays and lower costs for rivaroxaban compared with warfarin for venous thrombosis admissions. J Am Heart Assoc. 2016;5(10):e003788.

33. LaMori JC, Shoheiber O, Mody SH, Bookhart BK. Inpatient resource use and cost burden of deep vein thrombosis and pulmonary embolism in the United States. Clin Ther. 2015;37(1):62-70.

34. Margolis JM, Deitelzweig S, Kline J, et al. Pulmonary embolism inpatients treated with rivaroxaban had shorter hospital stays and lower costs compared with warfarin. Clin Ther. 2016;38(11):2496-2503.

35. Kahler ZP, Beam DM, Kline JA. Cost of treating venous thromboembolism with heparin and warfarin versus home treatment with rivaroxaban. Acad Emerg Med. 2015;22(7):796-802.

36. Kahler ZP, Beam DM, Kline JA. Immediate discharge of low-risk venous thromboembolism: A cost and safety analysis. SAEM 2014. 2014;21(5 Suppl. 1):S16-S17.

37. Shorr AF, Johnston S, Jing Y, et al. Real-world cost of all-cause hospitalizations over a 12-month period after acute venous thromboembolism. Circulation. 2014;130.

38. Coleman CI, Fermann GJ, Weeda ER, et al. Is Rivaroxaban associated with shorter hospital stays and reduced costs versus parenteral bridging to warfarin among patients with pulmonary embolism? Clin Appl Thromb Hemost. 2017;23(7):830-837.

39. Weeda ER, Wells PS, Peacock WF, et al. Hospital length-of-stay and costs among pulmonary embolism patients treated with rivaroxaban versus parenteral bridging to warfarin. Intern Emerg Med. 2017;12(3):311-318.

40. Raphael IJ, Mckenzie JC, Zmistowski B, Brown DB, Parvizi J, Austin MS. Pulmonary embolism after total joint arthroplasty: cost and effectiveness of four treatment modalities. $J$ Arthroplasty. 2014;29(5):933-937.

41. Lin J, Lingohr-Smith M, Kwong WJ. Incremental health care resource utilization and economic burden of venous thromboembolism recurrence from a U.S. payer perspective. J Manag Care Pharm. 2014;20(2):174-186.

42. Amin A, Bruno A, Trocio J, Lin J, Lingohr-Smith M. Incremental health care burden of bleeding among patients with venous thromboembolism in the United States. J Manag Care Spec Pharm. 2015;21(10):965-972.

43. Fanikos J, Rao A, Seger AC, Carter D, Piazza G, Goldhaber SZ. Hospital costs of acute pulmonary embolism. Am J Med. 2013;126(2):127-132.
44. Bookhart BK, Haskell L, Bamber L, Wang M, Schein J, Mody SH. Length of stay and economic consequences with rivaroxaban vs enoxaparin/vitamin K antagonist in patients with DVT and PE: findings from the North American EINSTEIN clinical trial program. J Med Econ. 2014;17(10):691-695.

45. Dasta JF, Pilon D, Mody SH, et al. Daily hospitalization costs in patients with deep vein thrombosis or pulmonary embolism treated with anticoagulant therapy. Thromb Res. 2015;135(2):303-310.

46. Weeda ER, Kohn CG, Peacock WF, et al. Rivaroxaban versus heparin bridging to warfarin therapy: impact on hospital length of stay and treatment costs for low-risk patients with pulmonary embolism. Pharmacotherapy. 2016;36(10):1109-1115.

47. Merli GJ, Hollander JE, Lefebvre P, et al. Costs of hospital visits among patients with deep vein thrombosis treated with rivaroxaban and LMWH/warfarin. J Med Econ. 2016;19(1):84-90.

48. Dubois C, Louzon P, Bhatheja R. Rivaroxaban vs. standard of care post ultrasound accelerated thrombolysis for pulmonary embolism. Critical Care Medicine. 2015;43(12):153.

49. Atay JK, Fiumara K, Piazza G, Fanikos J, Goldhaber SZ. Hospital budget implications of substituting dabigatran for warfarin in an anticoagulation service. Clin Appl Thromb Hemost. 2012;18(2):181-184.

50. Amin A, Bruno A, Trocio J, Lin J, Lingohr-Smith M. Real-world medical cost avoidance when new oral anticoagulants are used versus warfarin for venous thromboembolism in the United States. Clin Appl Thromb Hemost. 2016;22(1):5-11.

51. Amin A, Bruno A, Trocio J, Lin J, Lingohr-Smith M. Comparison of differences in medical costs when new oral anticoagulants are used for the treatment of patients with non-valvular atrial fibrillation and venous thromboembolism vs warfarin or placebo in the US. $J$ Med Econ. 2015;18(6):399-409.

52. Coleman CI, Baugh C, Crivera C, et al. Healthcare costs associated with rivaroxaban or warfarin use for the treatment of venous thromboembolism. J Med Econ. 2017;20(2):200-203.

53. Deitelzweig S, Laliberté F, Raut R, et al. Health care costs among patients diagnosed with deep vein thrombosis in the outpatient setting and treated with rivaroxaban versus low-molecular-weight heparin and warfarin. Value in Health. 2016;19(3):A45-A46.

54. Amin A, Bruno A, Trocio J, Lin J, Lingohr-Smith M. Estimated savings in medical costs when new oral anticoagulants are used for the treatment of patients with nonvalvular atrial fibrillation and venous thromboembolism vs. Warfarin in the U.S. Value in Health. 2015;18(3):A138.

55. Amin A, Jing Y, Trocio J, Lin J, Lingohr-Smith M, Graham J. Evaluation of medical costs associated with use of new oral anticoagulants compared with standard therapy among venous thromboembolism patients. J Med Econ. 2014;17(11):763-770.

56. Amin A, Jing Y, Trocio J, Lin J, Lingohr-Smith M, Graham J. Evaluation of medical costs avoided when new oral anticoagulants are used for extended treatment of venous thromboembolism based on clinical trial results. J Thromb Thrombolysis. 2015;40(2):131-138.

57. Choi M, Hector M. Management of venous thromboembolism for older adults in long-term care facilities. $J$ Am Acad Nurse Pract. 2012;24(6):335-344.

58. Bashir R, Zack CJ, Zhao H, Comerota AJ, Bove AA. Comparative outcomes of catheter-directed thrombolysis plus anticoagulation vs anticoagulation alone to treat lower-extremity proximal deep vein thrombosis. JAMA Intern Med. 2014;174(9):1494-1501.

59. Chen SY, Wu N, Gulseth M, et al. One-year adherence to warfarin treatment for venous thromboembolism in high-risk patients and its association with long-term risk of recurrent events. J Manag Care Pharm. 2013;19(4):291-301.

60. Fang MC, Fan D, Witt DM, et al. The association of warfarin control with pulmonary embolism mortality: the CVRN VTE study. Circulation. 2013;128(suppl_22).

61. Jean GW, Kelly K, Mathew J, Larumbe E, Hughes R. Venous thromboembolism treatment outcomes in cancer patients and effect of third-party payers on anticoagulant choice. Support Care Cancer. 2017;25(1):59-66. 
62. Levy MM, Bach C, Fisher-Snowden R, Pfeifer JD. Upper extremity deep venous thrombosis: reassessing the risk for subsequent pulmonary embolism. Ann Vasc Surg. 2011;25(4):442-447.

63. Liu X, Xie L, Phatak H, et al. Persistence on warfarin therapy in patients with venous thromboembolism: a large US insurance database analysis. Circulation. 2013;128(suppl_22).
64. Sussman M, Lim J, Wang C, Friedman M, Sander S, Griffiths R. Characteristics and treatment patterns of patients with deep vein thrombosis and/or pulmonary embolism in the US hospital setting. Blood. 2015;126(23):2061.

65. Xie L, Liu X, Phatak H, et al. Warfarin discontinuation in patients with unprovoked venous thromboembolism: a large US insurance database analysis. Am J Ther. 2016;23(6):e1744-e1753. 


\section{Supplementary materials \\ Search strategies}

Each search focused on articles that addressed inpatient (IP) and outpatient (OP) direct oral anticoagulant (DOAC) and vitamin $\mathrm{K}$ antagonist (VKA) treatment patterns for patients with venous thromboembolism (VTE) and was restricted to papers published in English since January 1, 2011. The PubMed/MEDLINE strategies appear in Tables S1 and S2, along with the number of abstracts retrieved.

Table SI MEDLINE clinical search strategy - conducted December I, 2016

\begin{tabular}{|c|c|c|}
\hline Step & Search terms & Abstracts \\
\hline I & $\begin{array}{l}\text { Search ((“Venous Thromboembolism”[Majr]) OR “Pulmonary Embolism”[Majr]) OR “Venous } \\
\text { Thrombosis”[Majr] }\end{array}$ & 63,522 \\
\hline 2 & $\begin{array}{l}\text { Search (venous thromboemboli*[Title] OR vte[Title] OR venous thrombosis[Title] OR venous } \\
\text { thromboses[Title] OR pulmonary thromboembolism*[Title] OR pulmonary embolism*[Title] OR deep } \\
\text { venous thrombosis[Title] OR deep vein thrombosis[Title] OR deep vein thromboses[Title] OR deep venous } \\
\text { thromboses[Title] OR dvt[Title]) } \\
\text { Note: Steps I and } 2 \text { are keyword terms and Mesh indexing terms that are specific to the indications of } \\
\text { interest. }\end{array}$ & 36,211 \\
\hline 3 & Search \#I OR \#2 & 69,728 \\
\hline 4 & $\begin{array}{l}\text { Search clinical outcome*[Title/Abstract] OR Tx outcome*[Title/Abstract] OR discharge*[Title/Abstract] OR } \\
\text { practice pattern*[Title/Abstract] OR Tx pattern*[Title/Abstract] OR patient management[Title/Abstract] OR } \\
\text { long-term management[Title/Abstract] OR long-term Tx*[Title/Abstract] OR extended Tx[Title/Abstract] } \\
\text { OR long-term care[Title/Abstract] OR extended care[Title/Abstract] OR outpatient*[Title/Abstract] OR } \\
\text { IP*[Title/Abstract] OR home health care[Title/Abstract] OR home self-care[Title/Abstract] OR switch*[Title/ } \\
\text { Abstract] OR transition*[Title/Abstract] OR nursing home*[Title/Abstract] OR rehabilitation[Title/Abstract] }\end{array}$ & $1,121,187$ \\
\hline 5 & $\begin{array}{l}\text { Search ((((“"Tx Outcome”[Mesh]) OR "Practice Patterns, Physicians"'[Mesh]) OR "Patient Discharge”[Mesh]) } \\
\text { OR “Long-Term Care”[Mesh]) OR “IPs"[Mesh]) OR “Ambulatory Care”[Mesh] } \\
\text { Note: Steps } 4 \text { and } 5 \text { outline key terminology and Mesh terms that are specific to the concept of Tx patterns } \\
\text { for IP and discharged patients. }\end{array}$ & 914,978 \\
\hline 6 & Search \#4 OR \#5 & $\mathrm{I}, 87 \mathrm{I}, 693$ \\
\hline 7 & Search \#3 AND \#6 & 10,207 \\
\hline 8 & $\begin{array}{l}\text { Search dabigatran[Title/Abstract] OR rivaroxaban[Title/Abstract] OR apixaban[Title/Abstract] OR } \\
\text { edoxaban[Title/Abstract] OR NOAC[Title/Abstract] OR anticoagulant*[Title/Abstract] OR VKA[Title/ } \\
\text { Abstract] OR vitamin K antagonist*[Title/Abstract] OR warfarin[Title/Abstract] }\end{array}$ & 66,882 \\
\hline 9 & $\begin{array}{l}\text { Search "Anticoagulants/therapeutic use"[Mesh] } \\
\text { Note: Steps } 8 \text { and } 9 \text { are used to focus results to the drugs of interest. }\end{array}$ & 50,512 \\
\hline 10 & Search \#8 OR \#9 & 94,383 \\
\hline II & Search \#7 AND \#I0 & 4,010 \\
\hline 12 & $\begin{array}{l}\text { Search prophylactic[Title] OR prophylaxis[Title] OR prevent*[Title] OR thromboprophyla*[Title] } \\
\text { Note: Step } 12 \text { is included to eliminate articles that are primarily focused on prophylactic Tx. }\end{array}$ & 289,300 \\
\hline 13 & Search \#II NOT \#I2 & 3,050 \\
\hline 14 & Search \#I3 NOT: Comment; Editorial; Letter; Meta-Analysis; Review & 2,179 \\
\hline 15 & Search \#|4 Filters: Publication date from 20I I/0I/0I to 20I6/I2/3I; English & 790 \\
\hline
\end{tabular}


Table S2 MEDLINE economic search strategy - conducted December I, 2016

\begin{tabular}{|c|c|c|}
\hline Step & Search terms & Abstracts \\
\hline I & $\begin{array}{l}\text { Search ((“Venous Thromboembolism”[Majr]) OR “Pulmonary Embolism”[Majr]) OR “Venous } \\
\text { Thrombosis”[Majr] }\end{array}$ & 63,522 \\
\hline 2 & $\begin{array}{l}\text { Search (venous thromboemboli*[Title] OR vte[Title] OR venous thrombosis[Title] OR venous } \\
\text { thromboses[Title] OR pulmonary thromboembolism*[Title] OR pulmonary embolism*[Title] OR deep } \\
\text { venous thrombosis[Title] OR deep vein thrombosis[Title] OR deep vein thromboses[Title] OR deep } \\
\text { venous thromboses[Title] OR dvt[Title]) } \\
\text { Note: Steps I and } 2 \text { are keyword terms and Mesh indexing terms that are specific to the indications of } \\
\text { interest. }\end{array}$ & 36,211 \\
\hline 3 & Search \#I OR \#2 & 69,728 \\
\hline 4 & $\begin{array}{l}\text { Search dabigatran[Title/Abstract] OR rivaroxaban[Title/Abstract] OR apixaban[Title/Abstract] OR } \\
\text { edoxaban[Title/Abstract] OR NOAC[Title/Abstract] OR anticoagulant*[Title/Abstract] OR VKA[Title/ } \\
\text { Abstract] OR vitamin K antagonist*[Title/Abstract] OR warfarin[Title/Abstract] }\end{array}$ & 66,882 \\
\hline 5 & Search "Anticoagulants/therapeutic use"[Mesh] & 50,512 \\
\hline 6 & Search \#4 OR \#5 & 94,383 \\
\hline 7 & Search \#3 AND \#6 & 13,720 \\
\hline 8 & $\begin{array}{l}\text { Search economic*[Title/Abstract] OR cost[Title/Abstract] OR costly[Title/Abstract] OR costs[Title/ } \\
\text { Abstract] OR price*[Title/Abstract] OR reimburs*[Title/Abstract] OR health resource utili*[Title/ } \\
\text { Abstract] OR resource utili*[Title/Abstract] OR resource use*[Title/Abstract] OR claim*[Title/Abstract] }\end{array}$ & 680,024 \\
\hline 9 & $\begin{array}{l}\text { Search “Economics"[Mesh]) OR "Health Care Costs"[Mesh] OR "Drug Utilization"[Mesh] OR "Health } \\
\text { Resources/utilization"[Mesh] } \\
\text { Note: Specific keywords and Mesh terminology in Steps } 8 \text { and } 9 \text { are incorporated to focus the results to } \\
\text { economic areas of interest. }\end{array}$ & 550,224 \\
\hline 10 & Search \#8 OR \#9 & $1,045,295$ \\
\hline $\mathrm{II}$ & Search \#7 AND \#I0 & 925 \\
\hline 12 & Search prophylactic[Title] OR prophylaxis[Title] OR prevent*[Title] OR thromboprophyla*[Title] & 289,300 \\
\hline 13 & Search \#II NOT \#I2 & 558 \\
\hline 14 & Search \#I3 NOT: Comment; Editorial; Letter; Meta-Analysis; Review & 339 \\
\hline 15 & Search \#I4 Filters: Publication date from 20II/0I/0I to 20I6/I2/3I; English & 116 \\
\hline
\end{tabular}

\section{Publish your work in this journal}

ClinicoEconomics and Outcomes Research is an international, peerreviewed open-access journal focusing on health technology assessment, pharmacoeconomics and outcomes research in the areas of diagnosis, medical devices, and clinical, surgical and pharmacological intervention. The economic impact of health policy and health systems organization also constitute important areas of coverage. The manuscript management system is completely online and includes a very quick and fair peer-review system, which is all easy to use. Visit http://www.dovepress.com/testimonials.php to read real quotes from published authors. 